\section{Pacific Northwest}

National Laboratory

Operated by Battelle for the

U.S. Department of Energy

\title{
Development of On-Board Fluid Analysis for the Mining Industry Final Report Project 40061
}

AF Pardini

August 2005

Prepared for the U.S. Department of Energy under Contract DE-AC05-76RL01830 


\title{
DISCLAIMER
}

This report was prepared as an account of work sponsored by an agency of the United States Government. Neither the United States Government nor any agency thereof, nor Battelle Memorial Institute, nor any of their employees, makes any warranty, express or implied, or assumes any legal liability or responsibility for the accuracy, completeness, or usefulness of any information, apparatus, product, or process disclosed, or represents that its use would not infringe privately owned rights. Reference herein to any specific commercial product, process, or service by trade name, trademark, manufacturer, or otherwise does not necessarily constitute or imply its endorsement, recommendation, or favoring by the United States Government or any agency thereof, or Battelle Memorial Institute. The views and opinions of authors expressed herein do not necessarily state or reflect those of the United States Government or any agency thereof.

\author{
PACIFIC NORTHWEST NATIONAL LABORATORY \\ operated by \\ BATTELLE \\ for the \\ UNITED STATES DEPARTMENT OF ENERGY \\ under Contract DE-AC05-76RL01830
}

Printed in the United States of America
Available to DOE and DOE contractors from the Office of Scientific and Technical Information,
P.O. Box 62, Oak Ridge, TN 37831-0062;
ph: (865) 576-8401
fax: (865) 576-5728
email: reports@adonis.osti.gov

\begin{abstract}
Available to the public from the National Technical Information Service, U.S. Department of Commerce, 5285 Port Royal Rd., Springfield, VA 22161 ph: (800) 553-6847 fax: (703) 605-6900

email: orders@ntis.fedworld.gov

online ordering: http://www.ntis.gov/ordering.htm
\end{abstract}

Ty This document was printed on recycled paper. 
PNNL-15299

\title{
Development of On-Board Fluid Analysis for the Mining Industry
}

\author{
Final Report
}

\section{Project 40061}

\author{
AF Pardini
}

August 2005

Prepared for

the U.S. Department of Energy

under Contract DE-AC05-76RL01830

Pacific Northwest National Laboratory

Richland, Washington 99352 


\section{Summary}

Chemical and physical analysis of a machine fluid can provide information about the condition of the fluid as well as the wear rates of the machine in which the fluid is used. Machine fluid analysis is widely used for determination of lubricant condition, lubricant contamination and wear status in engines, drive components and hydraulic systems in fleet or industrial service. In the mining industry, lubrication oil analysis is widely used as a component of on-condition maintenance programs. Typically, samples of engine oils, drive train lubricants and hydraulic fluids are taken at the mine and sent off-site to a commercial laboratory for analysis. The objective of the on-site analysis system is to reduce costs and turn-around time as well as provide timely information on machine and lubricant condition.

Pacific Northwest National Laboratory (PNNL: Operated by Battelle Memorial Institute for the Department of Energy) is working with the Department of Energy (DOE) to develop technology for the US mining industry. PNNL was awarded a three-year program to develop automated on-board/in-line or on-site oil analysis for the mining industry. This effort has been designated as the Mining Industry of the Future initiative at DOE Office of Industrial Technologies (OIT).

In year one of the project, a manufacturing prototype of an on-site in-line system (designated as "Lab-ina-Box") was built. In year two, feedback from the introduction of this technology gave strong direction that the technology should be made available in an on-site/off-line configuration (as opposed to an on-site and on-line configuration dedicated to one machine). The off-line or standalone configuration allowed the Lab-in-a-Box to be more effectively used by providing fast turn-around oil analysis on multiple machines. Year three produced a system that could be deployed at a mine site with Internet-based links to remote expert systems and personnel for data interpretation. The major milestones and status provides a description of the project to date.

\section{-Planned Milestone}

- Design and fabricate prototype bench-top system for diesel lube oils

- Optimize sensors and software for use with synthetic oils found in hydraulic systems

- Demonstrate system technology at Kennecott Copper Mine Site in South Jordan, UT.

- Fabricate and demonstrate on-board/on-site fluid analysis systems for mining equipment

\section{Scheduled}

$06 / 2000$

$09 / 2000$

$08 / 2001$

$04 / 2003$
Completed

$06 / 2000$

$10 / 2000$

$09 / 2001$

$04 / 2003$

The final disposition of the equipment developed under this project is at PNNL facility 2400 Stevens. 


\section{Contents}

PROJECT SUMMARY ..................................................................................... i

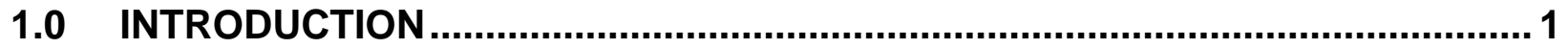

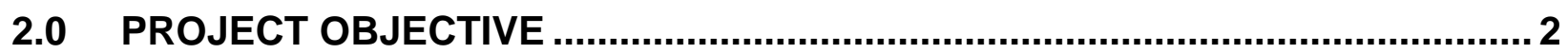

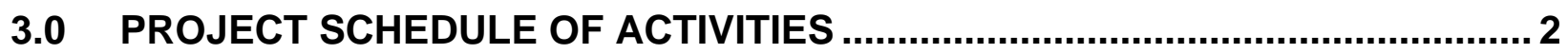

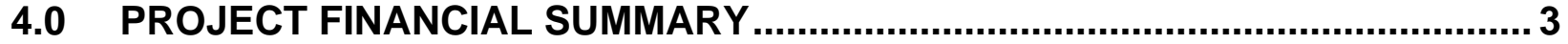

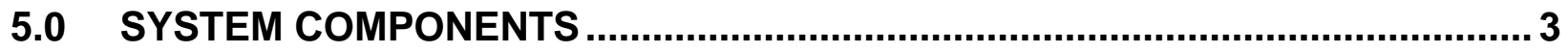

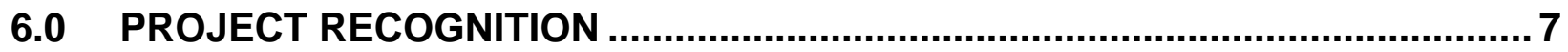

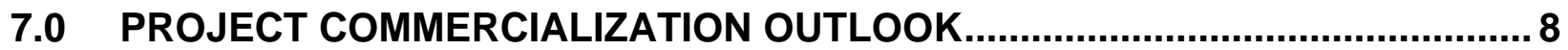

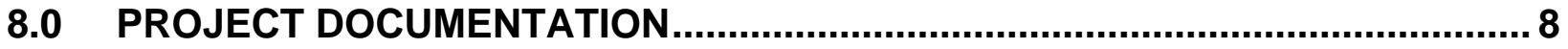




\section{Figures}

Figure 1 Overview of Forward Deployed Automated Machine Fluid Analysis ....................... 1

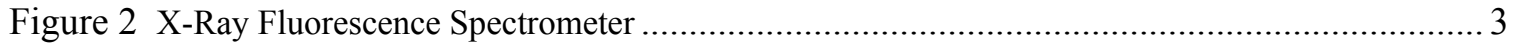

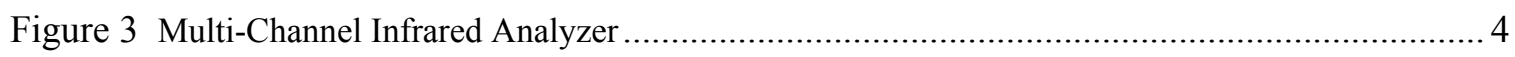

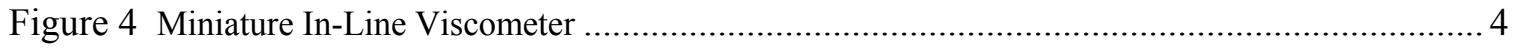

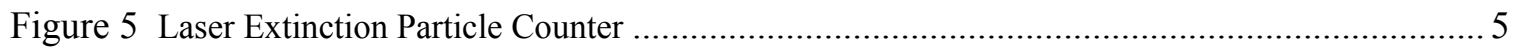

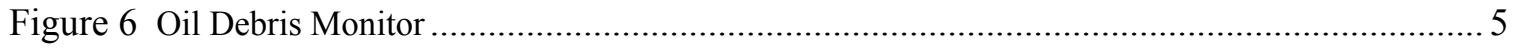

Figure 7 Sample Bottle Handling/Routing/and Flow Control Module.............................................. 6 


\subsection{Introduction}

The development of the machine fluid analysis systems began in fiscal year 1999 at the Pacific Northwest National Laboratory (PNNL) under the DOE OIT Mining Industry of the Future program. It was anticipated that the program would last 36 months; however it was extended at no additional cost until the end of fiscal year 2004.

The state-of-the-art Lab-in-the-Box technology diagnoses and predicts the condition of engine and drive machinery almost instantaneously. It provides many industries - trucking, mining, railroad, aircraft and shipping - as well as the military, instant access to crucial information about the condition of lube oils and the machines in which they are used.

This technology eliminates the need for the costly and time-consuming process of taking fluid samples, shipping them to a laboratory for analysis and waiting days for results. The LIAB brings the laboratory to the machine. The technology can be adapted for use on most fluids (such as lube oil, hydraulic oil, fuel) used in many kinds of machinery including stationary diesel and gas turbine engines, mining equipment, aircraft, ships and military equipment - almost any high-value engine or machine.

Response from the mining community indicated the need for an off-line or standalone configuration which would allow LIAB to be more effectively used by providing fast turn-around oil analysis on multiple machines. Based on this response, the system design incorporated a forward deployed Oil Analysis and is depicted in Figure 1.

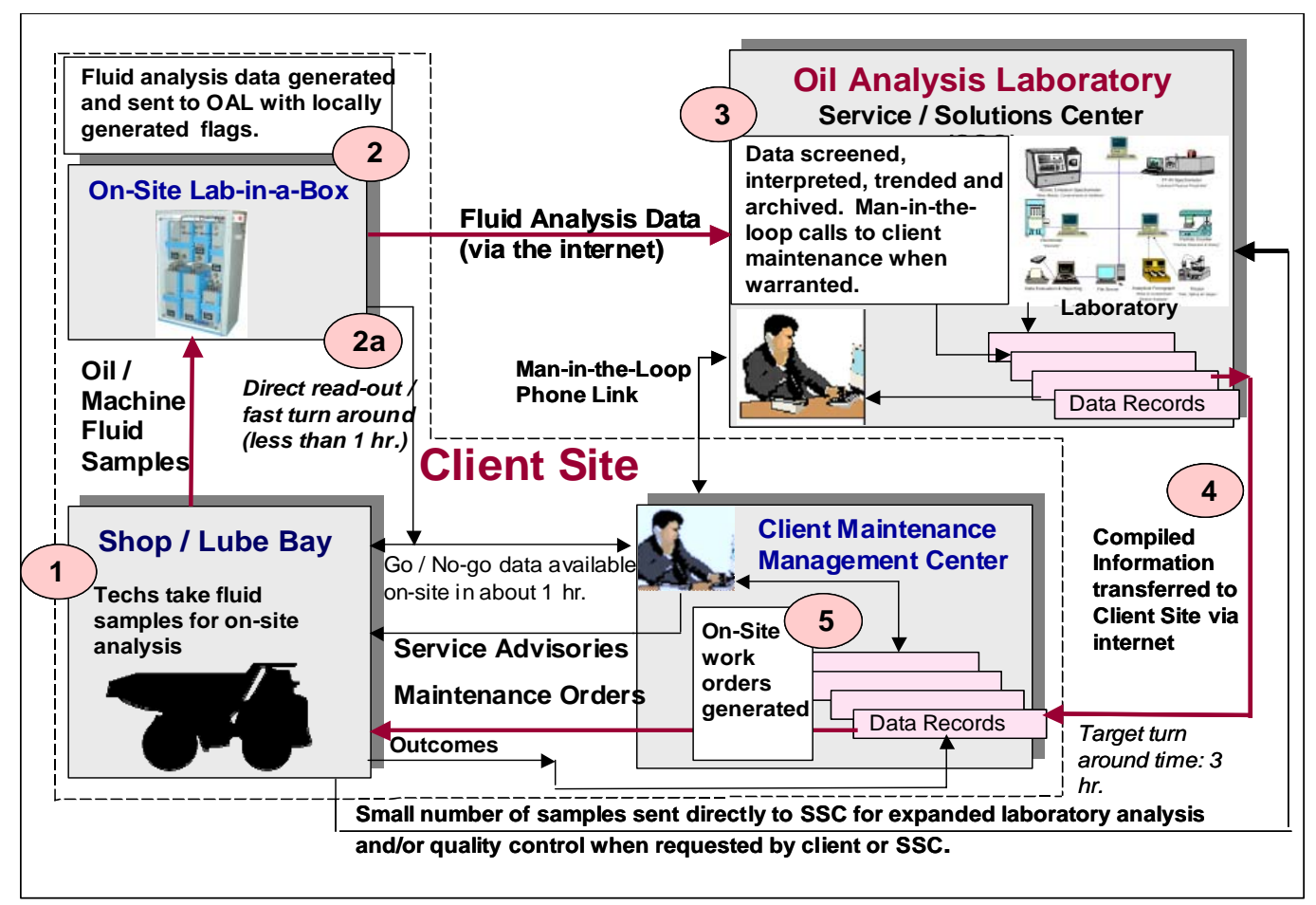

Figure 1. Overview of Forward Deployed Automated Machine Fluid Analysis 


\subsection{Project Objective}

The objective of this project was to:

- Develop systems that allow on-board or on-site analysis of lubricating and hydraulic fluids for mining equipment, to provide near real-time diagnostic / prognostic information on equipment health

- Implement advanced condition-based maintenance systems to decrease downtime, increase equipment life, enable more efficient equipment use, and reduce oil in waste streams

\subsection{Project Schedule of Activities}

\section{Planned Milestones}

- Design and fabricate prototype bench-top system for diesel lube oils June 2000

- Optimize sensors and software for use with synthetic oils found in hydraulic systems September 2000

- Demonstrate system technology at Kennecott Copper Mine Site in South Jordan, UT. August 2001

- Fabricate and demonstrate on-board/on-site fluid analysis systems for mining equipment April 2003 


\subsection{Project Financial Summary}

Accrued costs: \$ 849,962 as of: 30 September, 2004

Invoiced costs: \$ 849,962 as of: 30 September, 2004

(Dollars in Thousands)

\begin{tabular}{|l|r|r|r|r|r|r|r|r|r|r|r|}
\hline & \multicolumn{2}{|c|}{ CY 1999} & \multicolumn{2}{c|}{ CY 2000} & \multicolumn{2}{c|}{ CY 2001} & \multicolumn{2}{c|}{ CY 2002-2004 } & \multicolumn{2}{|c|}{ Total } \\
\hline & Plan + & Actual $^{*}$ & Plan + & Actual & Plan + & Actual & Plan + & Actual & Plan & Actual \\
\hline Participant & 0 & 0 & 342 & 329 & 265 & 231 & 295 & 148 & 902 & 708 \\
\hline DOE & 89 & 79 & 267 & 239 & 270 & 238 & 224 & 294 & 850 & 850 \\
\hline \multicolumn{1}{|c|}{ Total } & 89 & 79 & 609 & 568 & 535 & 469 & 519 & 442 & 1,752 & 1,558 \\
\hline
\end{tabular}

Key:

+ Planned costs for the full year

*Actual costs through the reporting period; DOE costs do not include expenditures that may have been incurred by lab but have not yet been drawn from DOE accounts

\subsection{System Components}

On-site Fluid Analysis Technology provides near real-time analysis of machine fluid condition and advises management when fluid parameters are outside specified limits. The system development was comprised of the following analytical modules and software components:

\section{XRF Spectrometer}

Energy dispersive $\mathrm{x}$-ray spectrometer comprising a ${ }^{109} \mathrm{Cd}$ source, and $\mathrm{x}$-ray detector with 256 or 512 channel multichannel analyzer for quantitative determination of wear or additive metals including $\mathrm{Fe}, \mathrm{Cr}, \mathrm{Ni}, \mathrm{Mo}, \mathrm{Cu}, \mathrm{Pb}, \mathrm{Zn}$, Ag, Sn, V, Co, and Ti. (EDAX CT 5000).

\section{X-Ray Fluorescence Spectrometer}

Wear Metals Detection:

- Small, lightweight sensor

- Sealed x-ray source

- Accurate measurements

- Continuous monitoring

- No moving parts

Pacific Northwest

National Laboratory

Ousaded by lined if ex the

Figure 2 X-Ray Fluorescence Spectrometer 


\section{NDIR Infrared Analyzer}

Non-dispersive multi-channel infrared system for determination of water, oxidation, ester breakdown, nitration, sulfation, and fuel dilution in crankcase and gear lube oils as well as hydraulic fluids. (FIRM 57 upgraded to ARAS48).

\section{Electromechanical Viscometer}

Miniature viscometer for determination of temperature compensated dynamic viscosity to better than $1.4 \%$ at $0.8 \%$ precision. (CASI STL 570 upgraded to ViscoPro 1500).

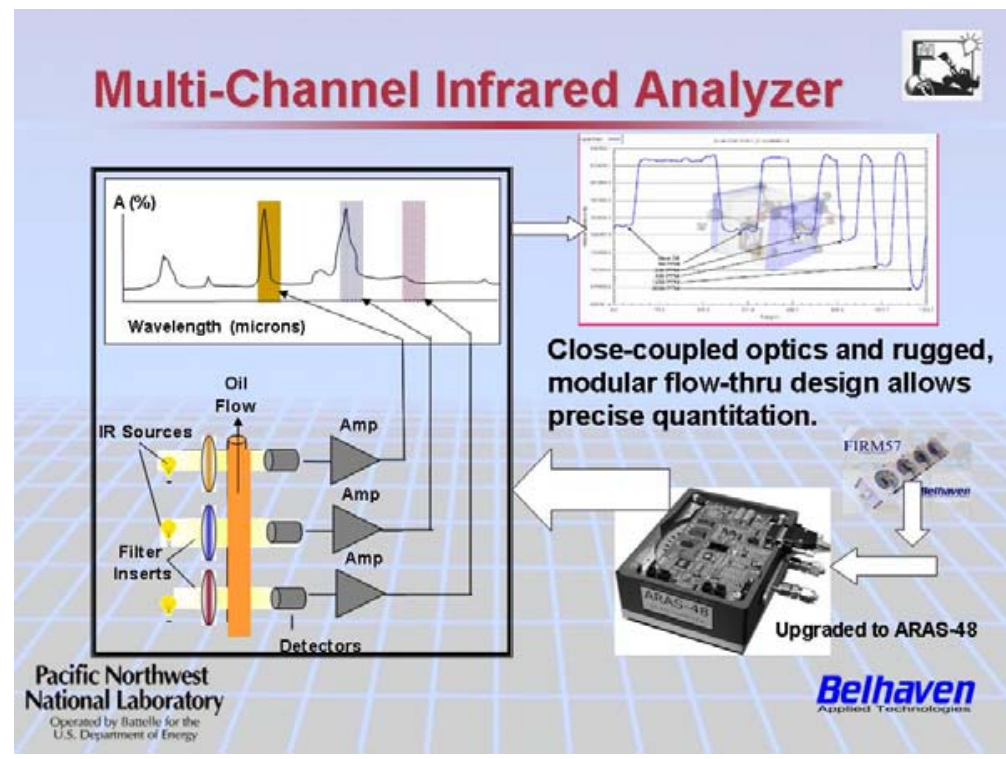

Figure 3 Multi-Channel Infrared Analyzer

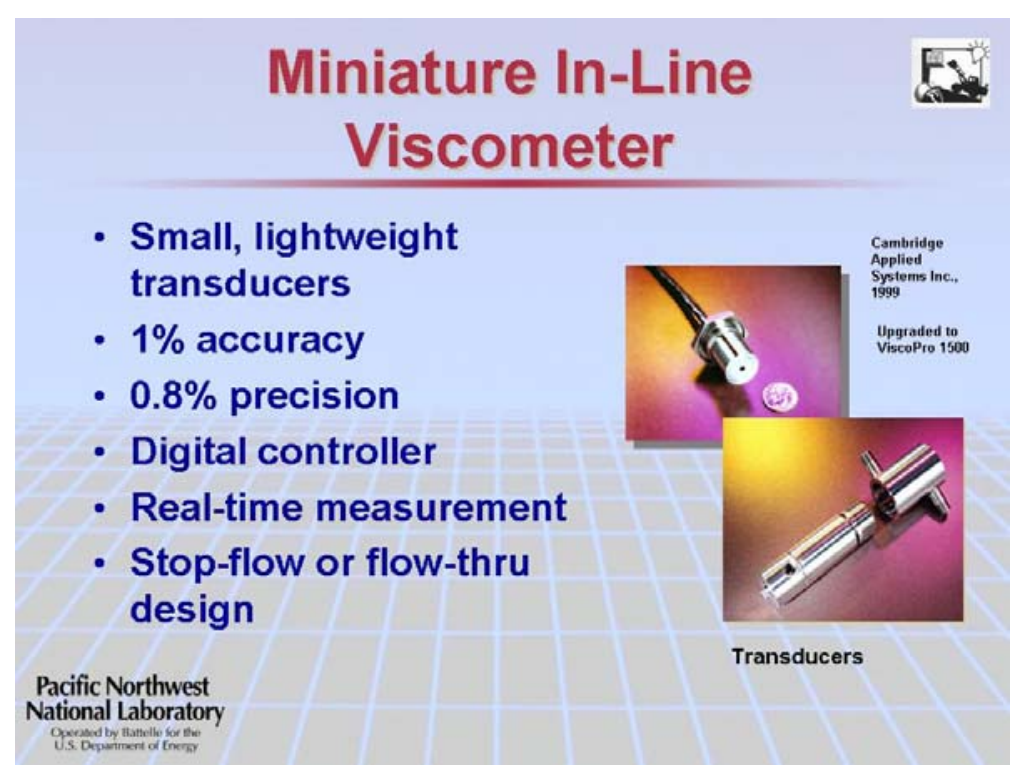

Figure 4 Miniature In-Line Viscometer 


\section{Laser Extinction Particle Counter}

Determination of particles counts in eight size channels adjustable from 5 microns to $100+$ microns. (ARTI PODS Derivative).
Debris monitor. Monitors Ferrous and Non-ferrous wear particles. Minimum Ferrous particle size is 70 microns, minimum Non-ferrous particle size is 280 microns.

\section{Laser Extinction Particle Counter}

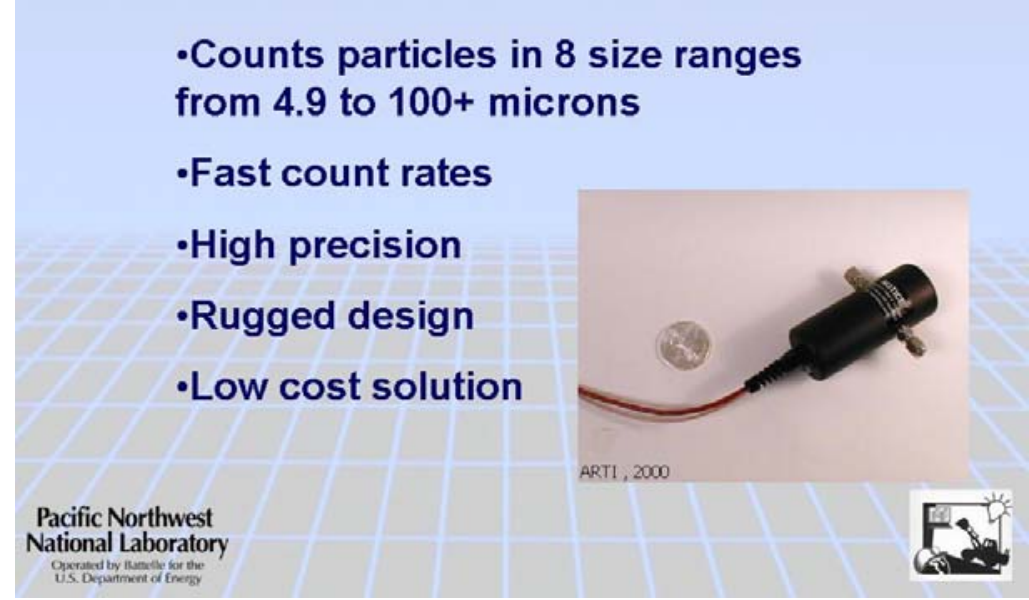

Figure 5 Laser Extinction Particle Counter

\section{Oil Debris Monitor}

- In-line system

- Determines approximate mass of ferromagnetic and non-ferromagnetic particles

- Trends particle counts and total particle mass

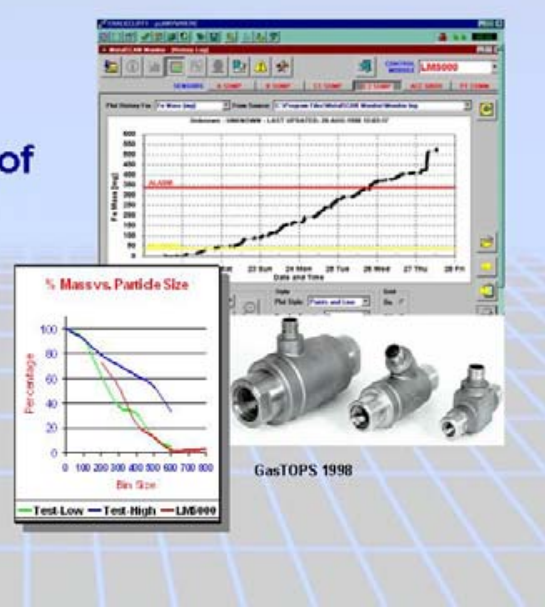

Figure 6 Oil Debris Monitor 
Multi-Sample Introduction System Battelle / Belhaven / OAL System for on-site introduction of oil samples for analysis.

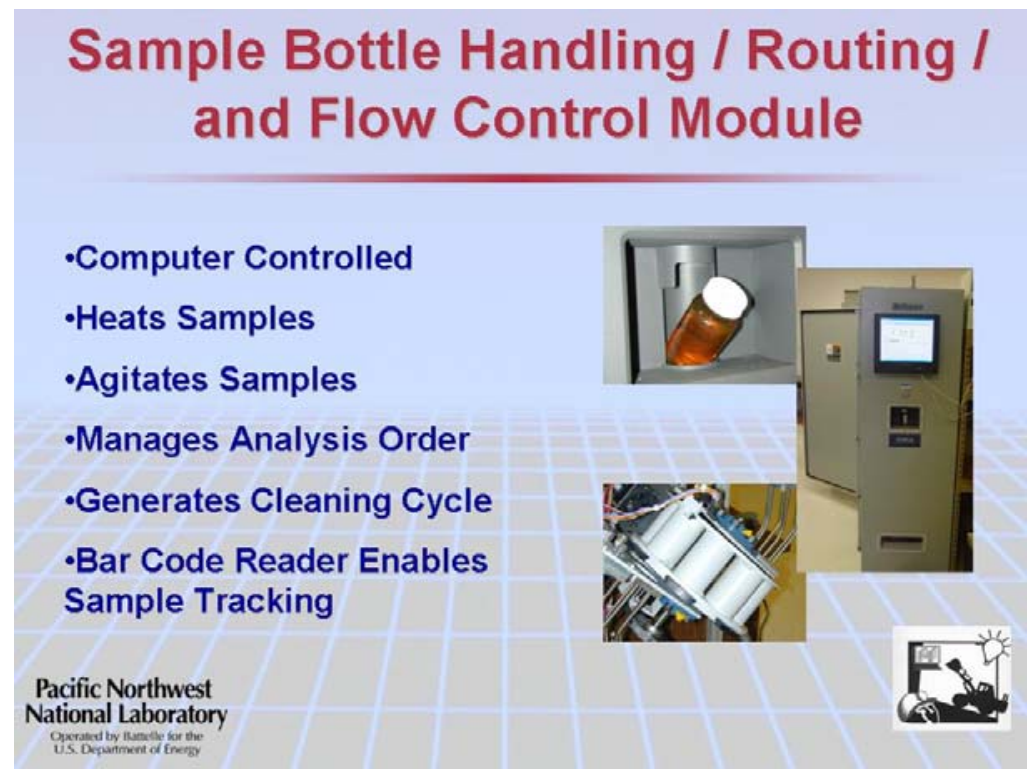

Figure 7 Sample Bottle Handling/Routing/and Flow Control Module

\section{System Command and Control Module}

Advantix 586 computer system with Battelle OASCCM software providing TCP/IP compatibility with the Internet and local user interface.

\section{Sample Acquisition and Management System}

BAT SAS 200 system for sample conditioning prior to analytical module analysis.

\section{Software:}

Bulk XRF (EDAX fundamental parameters software for "Lab-in-a-Box".

OASCCM (Battelle NT-based operating system for "Lab-in-a-Box".

Battelle "Lab-in-a-Box" User Interface

Data base software to be selected (Dingo is recommended).

AC Power Supply and Controller, System Case and Hardware 


\subsection{Project Recognition}

The development of the machine fluid analysis system has produced considerable recognition for the laboratory. Papers written and presented include:

Wilson, B.W. and Silvernail, G: "Automated In-Line Machine Fluid Analysis for Marine Diesel and Gas Turbine Engines," Proceedings: Technology Showcase 2002, JOAP International Condition Monitoring Conference, Mobile AL, April 7-11 2002.

Wilson, B.W., NH Hansen, G, Silvernail, B.Cross: "Modular System for Multi-Parameter In-Line Machine Fluid Analysis." Proceedings: Technology Showcase 2000, JOAP International Condition Monitoring Conference, Mobile, AL. April 3-6 2000. Joint Oil Analysis Program Technology Center Pensacola.

Wilson, BW and Price LS:On-Board X-Ray Fluorescence Analysis System. Lubrication and Fluid Power, Vol. 1 pp 36-38 (2000).

Wilson, B. W., N. H. Hansen, C. L. Shepard, T. J. Peters, and F. L. Greitzer: "Development of a Modular In-Situ Oil Analysis Prognostic System." Proceedings, SOLE '99 Symposium, Las Vegas, NV. 1999.

Intellectual Property that has been generated in the area of In-line Fluid Analysis include:

\section{Apparatus and Method for Fluid Analysis}

Battelle No. 12220-E

Patent No. 6,561,010

\section{An Apparatus for Machine Fluid Analysis}

Battelle No. 12092-B

Patents pending in Australia and Europe. Application nos. 16200/01 (Australia) and 00978775.5 (EPC)

Method and Apparatus to Predict the Remaining Service Life of an Operating System Battelle No. 12241-E

Patent Pending. Application nos. PCT/US00/23389 \& 10/362,717 
Diagnostics/Prognostics Using Wireless Links

Battelle No. 12898-B

Patent No. 6,662,091

Compact X-Ray Fluorescence Spectrometer and Method for Fluid Analysis

Battelle No. 13093-B

Patent No. 6,668,039

Dual X-Ray Fluorescence Spectrometer and Method for Fluid Analysis

Battelle No. 13610-E

Patent Pending. Application no. 10/420,460

\subsection{Project Commercialization Outlook}

- A non-exclusive license for manufacture, sale and use of the technology developed under this program has been granted to Belhaven Applied Technologies in Kennewick, WA.

- PNNL entered into negotiations with Lexten Corp. for a license and demonstration of the existing unit at a US mine site.

- US Patent Number 6,561,010 for an Apparatus and method for fluid analysis was granted on May $13,2003$.

- DOE OIT project industrial partners have first-in-line rights to license background intellectual property.

\subsection{Project Documentation}

The attachments to this document provide the project documentation for the final report. 


\section{Attachment 1 \\ On-site system specification}

\section{Portable Lubricating Oil and Hydraulic Fluid Analysis System Specifications}

The AutOLab ${ }^{\mathrm{TM}}$ oil analysis system uses multiple field-hardened instruments to make laboratory quality measurements of oil or hydraulic fluid condition on a near real time basis. The modular approach taken with the AutOLab ${ }^{\mathrm{TM}}$ system allows the customer to choose the right combination of instruments for their needs. This approach also allows for the easy integration of new instruments as they become available. The instruments that have been used to date include:

1. Non-dispersive Infrared Analysis (NDIR),

2. X-ray Fluorescence Spectrography (XRF),

3. Electromechanical Viscometer,

4. Laser Extinction Particle Counter, and

5. In-line Debris Monitor.

Some of the parameters that can be measured with these instruments include:

1. Water content (NDIR),

2. TAN/TBN (NDIR),

3. Additive condition (NDIR),

4. Oxidation/Sulfation (NDIR),

5. Contamination (NDIR, particle counter and XRF),

6. Elemental wear and contamination analysis (XRF),

7. Viscosity,

8. Solid particle contamination, and

9. Ferrous and non-ferrous debris particles.

The specifications for each component are listed below along with a comparison with the Joint Oil Analysis Program (JOAP) requirements for the Army. Where possible, comparisons of AutOLab ${ }^{\mathrm{TM}}$ instruments with standard oil analysis lab measurements are included.

Non-dispersive infrared analysis. Can measure infrared absorption for up to 32 channels in the 2.5 to 12 micron range (other ranges can be requested). Typical precision per band is given in Table 1 below.

\begin{tabular}{|l|l|l|l|l|}
\hline Wavelength (microns) & 0.8 & 2.9 & 5.7 & $6-9$ \\
\hline $\begin{array}{l}\text { Precision (average percent } \\
\text { error) }\end{array}$ & 0.4 & 0.013 & 0.23 & 0.62 \\
\hline
\end{tabular}

Table 1. Typical precision per band for non-dispersive infrared analyzer. 
A comparison of NDIR results with standard laboratory measurements for water and TAN are given in Table 2 below. The NDIR is capable of measuring water content to $50 \mathrm{ppm}$ or less.

\begin{tabular}{|c|c|c|c|}
\hline System/Laboratory & \multirow[t]{2}{*}{ NDIR Spectroscopy } & \multirow[t]{2}{*}{ Oil Analysis Lab* } & \multirow[t]{2}{*}{ Navy Lab** } \\
\hline Parameter & & & \\
\hline Water Sample \#1 & $410 \mathrm{ppm}$ & $430 \mathrm{ppm}$ & $370 \mathrm{ppm}$ \\
\hline Water Sample \#2 & $440 \mathrm{ppm}$ & $450 \mathrm{ppm}$ & $380 \mathrm{ppm}$ \\
\hline TAN Sample \#1 & $0.70 \mathrm{mg} \mathrm{KOH} / \mathrm{g}$ & $0.70 \mathrm{mg} \mathrm{KOH} / \mathrm{g}$ & $0.64 \mathrm{mg} \mathrm{KOH} / \mathrm{g}$ \\
\hline TAN Sample \#2 & $0.77 \mathrm{mg} \mathrm{KOH} / \mathrm{g}$ & $0.70 \mathrm{mg} \mathrm{KOH} / \mathrm{g}$ & $0.64 \mathrm{mg} \mathrm{KOH} / \mathrm{g}$ \\
\hline \multicolumn{4}{|c|}{$\begin{array}{l}\text { * Data provided by Oil Analysis Lab, Spokane, Wa } \\
\text { * Water by Karl Fischer, ASTM D1744, TAN by ASTM D664 }\end{array}$} \\
\hline
\end{tabular}

Table 2. Comparison of NDIR results with laboratory measurements.

X-ray fluorescence spectroscopy. The standard source configuration for the XRF is ${ }^{109}$ Cadnium. There is no limit on the particle size for x-ray fluorescence spectroscopy measurements. Table 3 below lists the elemental detection limits at 10 percent precision for the standard configuration for the AutOLab ${ }^{\mathrm{TM}}$ compared with the calibration requirements for AOAP.

\begin{tabular}{|l|l|l|l|l|l|}
\hline Element & $\begin{array}{l}\text { Detection } \\
\text { Limit (ppm) }\end{array}$ & $\begin{array}{l}\text { AOAP } \\
\text { Calibration } \\
(\mathbf{p p m})\end{array}$ & Element & $\begin{array}{l}\text { Detection } \\
\text { Limit (ppm) }\end{array}$ & $\begin{array}{l}\text { AOAP } \\
\text { Calibration } \\
\mathbf{( p p m )}\end{array}$ \\
\hline Aluminum & $\mathrm{ns} *$ & 10 & Nickel & $5-10$ & 10 \\
\hline Boron & $\mathrm{ns}$ & 100 & Silicon & $\mathrm{ns}$ & 10 \\
\hline Chromium & $1-3$ & 10 & Silver** & $1-3$ & 10 \\
\hline Copper & $5-10$ & 10 & Sodium & $\mathrm{ns}$ & 10 \\
\hline Iron & $1-3$ & 10 & Tin & 10 & 10 \\
\hline Lead & $1-3$ & Titanium & $3-5$ & 10 \\
\hline Magnesium & $\mathrm{ns}$ & Zinc & $1-3$ & 100 \\
\hline Molybdenum & $3-5$ & 10 & & \\
\hline$*$ ns $=$ Not in standard configuration of XRF. & & & \\
\hline$* *$ Requires ${ }^{241}$ Americium source. & & & \\
\hline
\end{tabular}

Electromechanical viscometer. The standard ranges for the viscometer are viscosities from 2.5 to $50 \mathrm{cP}$ and from 25 to $500 \mathrm{cP}$ (other ranges available) with a repeatability of 0.1 percent. The AOAP calibration requirement is 6.75 to $430 \mathrm{cP}$.

Laser extinction particle counter. Can monitor particle size in up to 8 ranges between 4 and 100 microns. Is calibrated to ISO 11171:2000 standards (4, 6 and 14 microns). 
Debris monitor. Monitors Ferrous and Non-ferrous wear particles. Minimum Ferrous particle size is 70 microns, minimum Non-ferrous particle size is 280 microns.

\section{Notes:}

1. It is important to keep in mind that this system was not designed to completely replace laboratory oil analysis. Its main purpose is to allow the user to determine several key parameters in the field in order to assess the condition of the oil on a near real time basis. This may provide adequate analysis in itself or serve as a screening mechanism to determine which samples, if any, require more detailed study.

2. AutOLab is a trademark of Belhaven Applied Technologies, Inc. 
Attachment 2

System Design

Attach 1 


\section{AutoSampler PCA System}

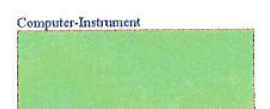

DWG No. E-0110-004-0
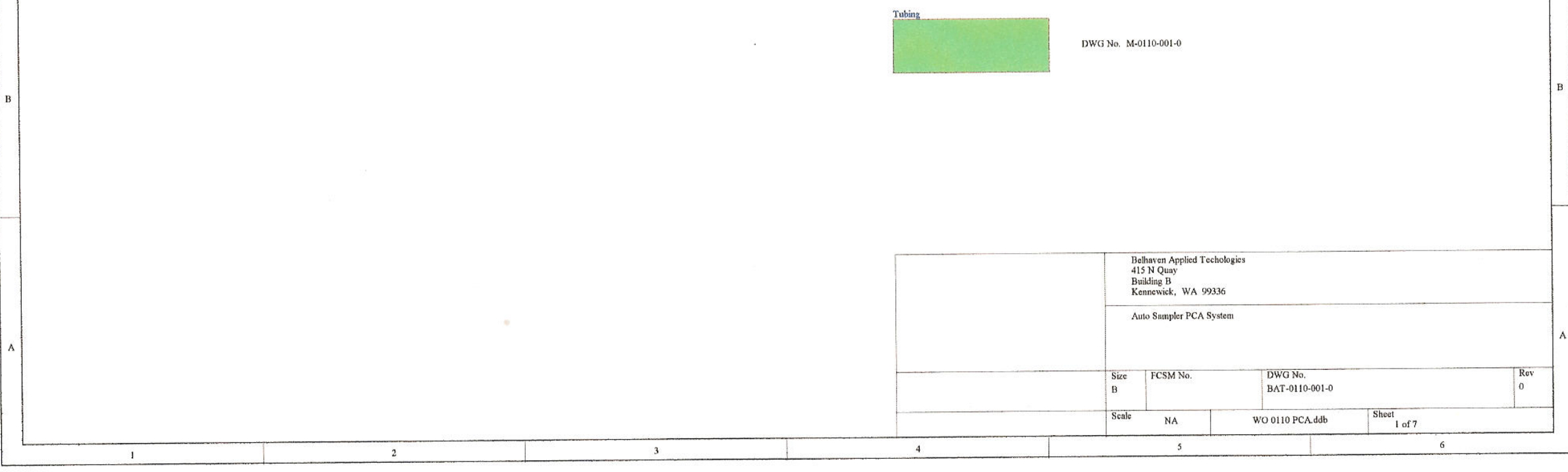


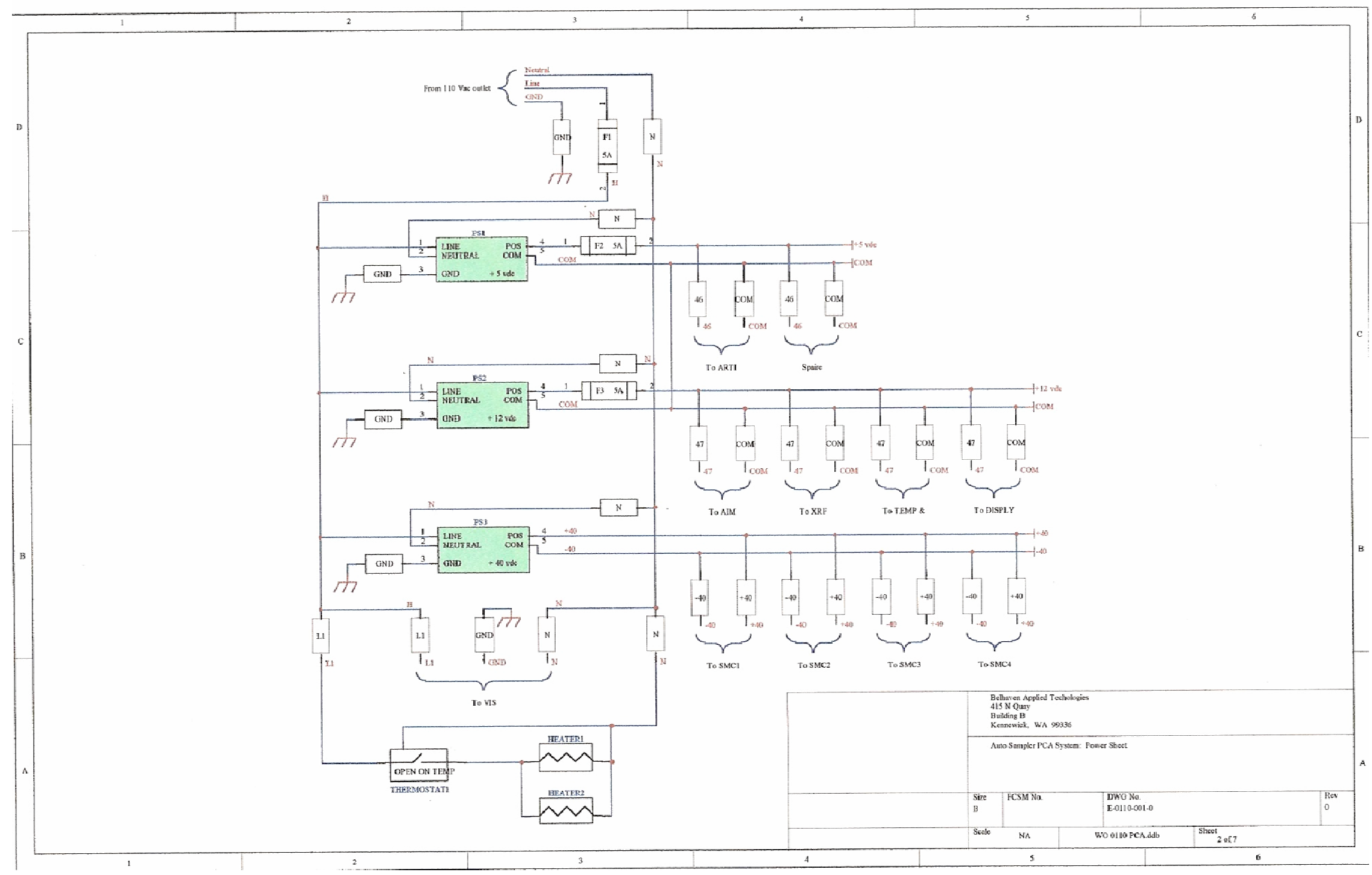




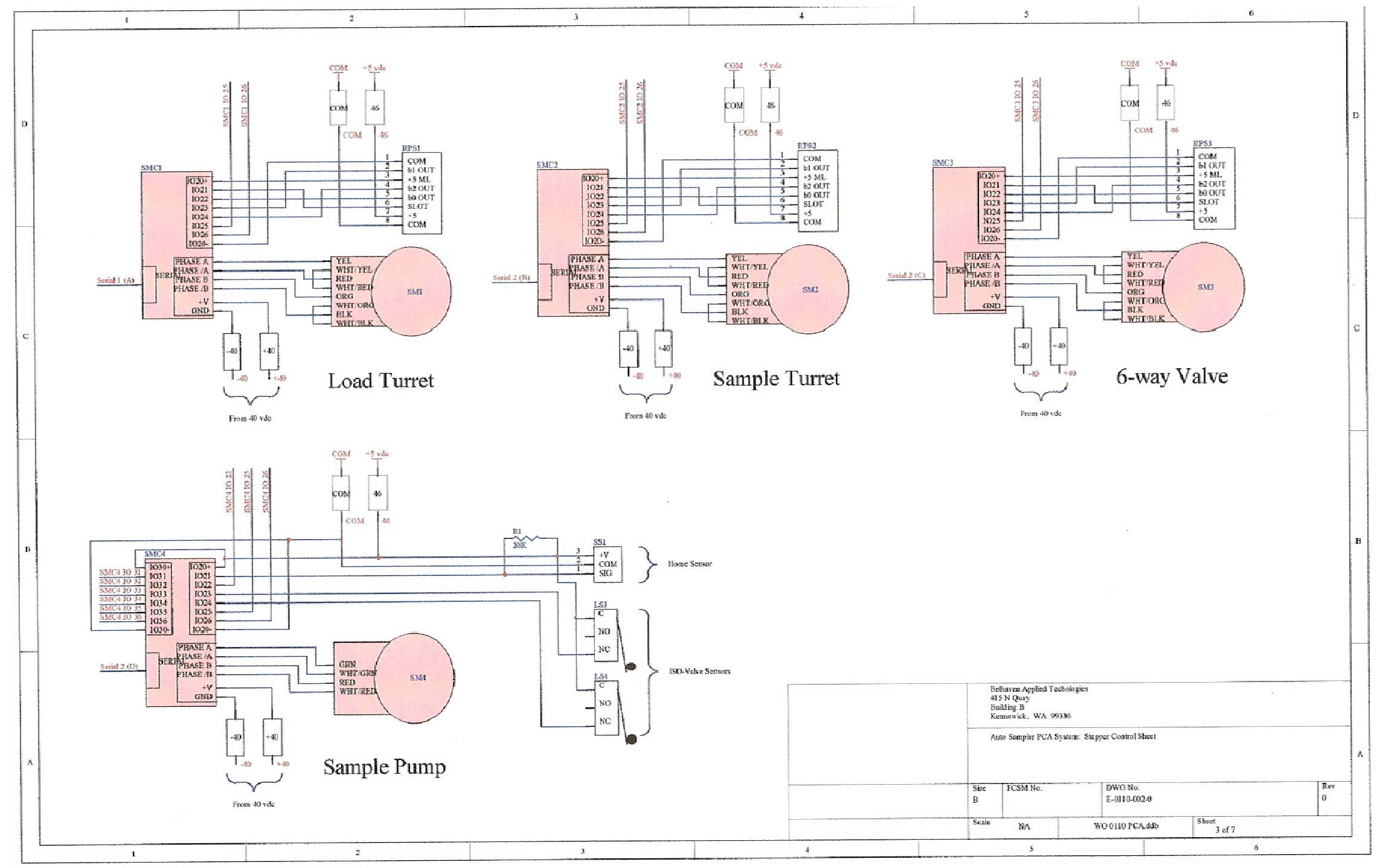




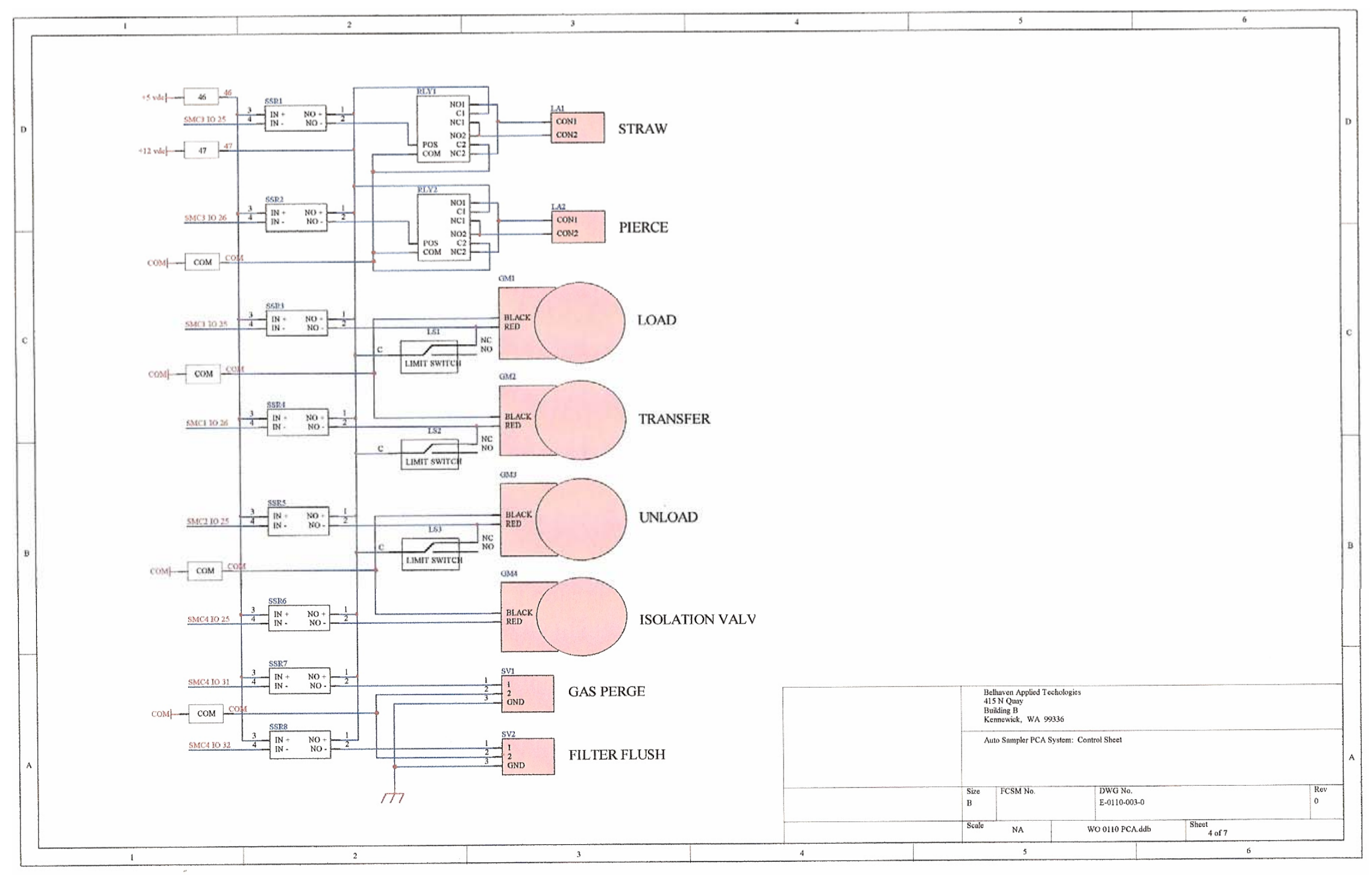




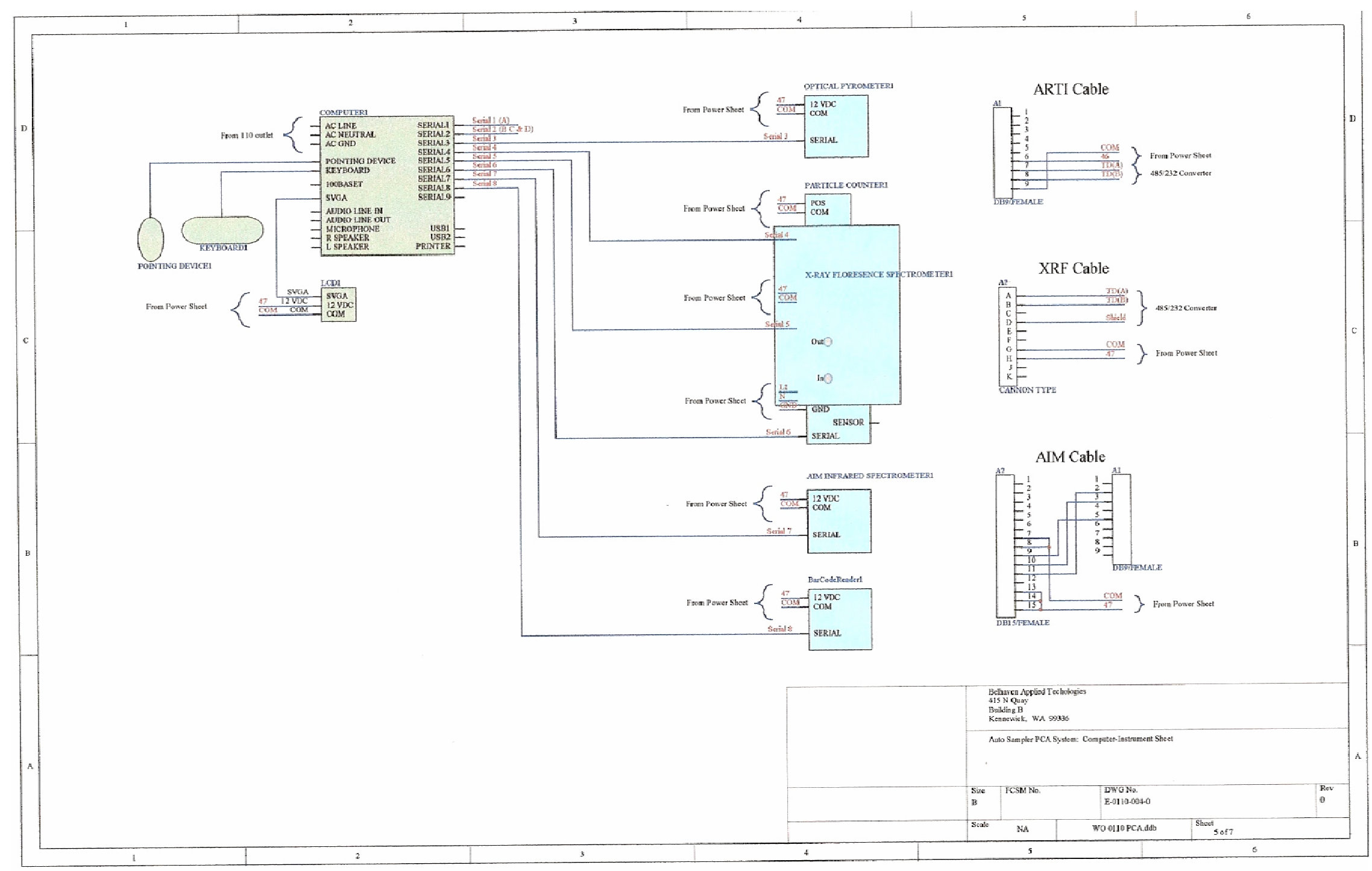




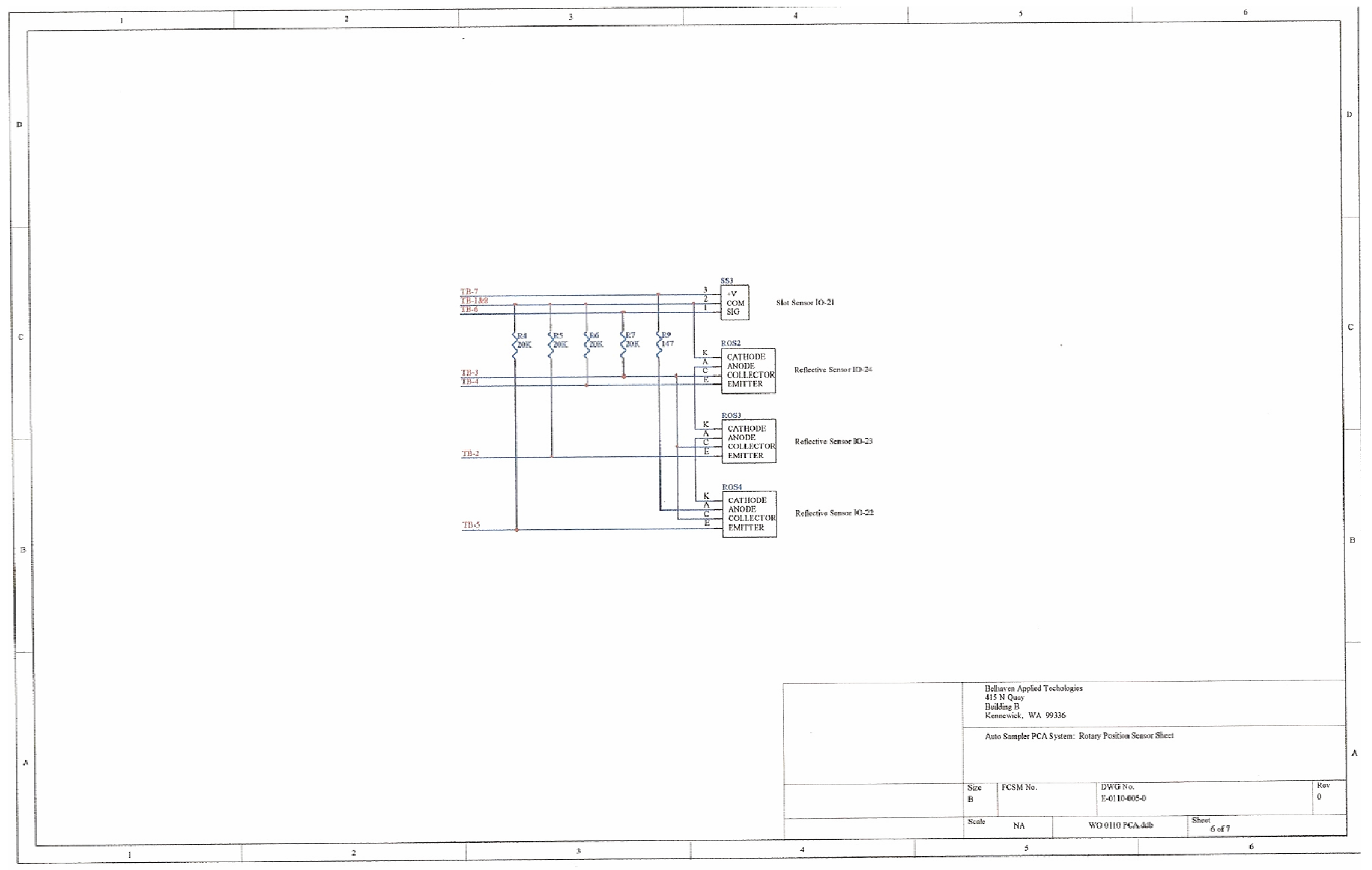




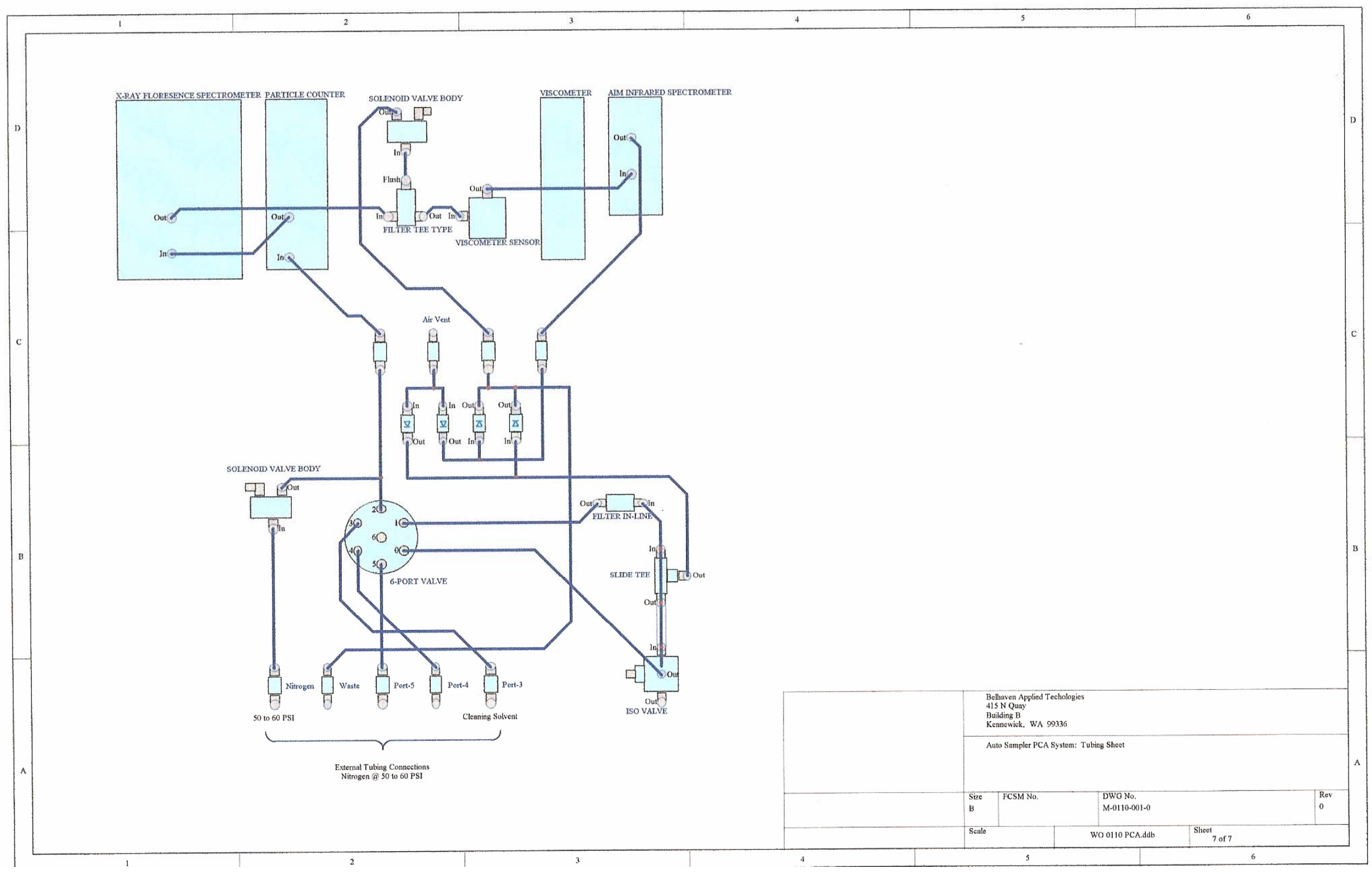




\section{Attachment 3 \\ Operating Manual PNNL 14821}

\section{Lab-in-a-Box Software Operating Manual PNNL-14821}

\section{Introduction}

The Lab-in-a-Box (LIAB) consists of four instruments commonly used in machine fluid analysis. These instruments are a viscometer, a particle counter, a XRF elemental analyzer and a Non-dispersive infrared analyzer. These four instruments are linked through a common flow path with an automatic sampling unit that holds up to 9 test specimens, including the sample being tested. The instruments and the sampling unit are controlled using a LabView software master program. All control is through serial port commands. The remainder of this manual summarizes the use of this master program. Information and specifications for the different instruments can be found of the Appendices of this manual.

All samples introduced into the LIAB must have a barcode. If the sample does not have a barcode, the LIAB will not accept the sample.

The normal operating procedure for a sample run is as follows:

1. If there are any changes to the settings for the particular run they must be made before starting the LabView program. The functions of the different settings in the master program are described later in this manual. These settings will be in effect until the program is stopped and restarted. The program will then revert to the default settings. If there are a particular set of operations settings that are used on a routine basis, it is recommended that they be written down for future reference. The current version of LabView used to make the executable version of the Master Program does not allow changes to the default settings.

2. The program is started by clicking on the arrow in the upper left corner of the program screen. Once the master program is started, the sample is placed in the sample door and slowly rotated until the barcode is read. The unit will beep when it has read the barcode. The door will open and the sample will be accepted. If the unit is busy with other operations, it may take a few moments before the sample is taken into the unit.

3. Continue loading the samples into the unit until it is full or until the desired number of samples has been introduced. The front panel will indicate the sample status. This is described more fully below.

4. When the testing of a sample is complete, it will exit through the door in the bottom of the unit.

5. When all of the desired samples have been tested, the program should be stopped and the data can be retrieved from the $\mathrm{C}:$ autosamplerldata directory. The program can be stopped by pressing the stop button in the lower right hand corner of the Monitor Screen.

\section{Data Files}

The data files that result from an analysis can be found in the directory C: $\mid$ autosamplerldata. The naming convention for the data files is as follows:

User provided name-Dmonth_day_year-Thour_min_sec.csv 
Where the date and time are the date and time that the file was created. All data until the program is stopped is written to this file. The naming convention prevents data from being overwritten and allows the files to be tracked by when they were created. The data files are flat text files with tab separators. A file utility has been provided with the master program to convert these files into comma separated files so that they can be imported directly into Excel. The files can be introduced into most other software using the import function. The setup of the headers is described in the section on the File Configuration Screen described below. In addition to the data provided below, the file setup uses the data in the NDIR

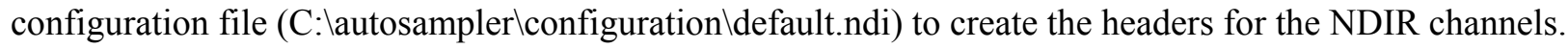
The wavenumbers for these channels have been pre entered in the File Configuration Screen.

\section{File Configuration Screen}

Figure 1 shows the file configuration screen. This screen is used to set the directory for data files, set the initial part of the data file name, to add comments to a data file and set the data file headers. Each function is described in more detail below.

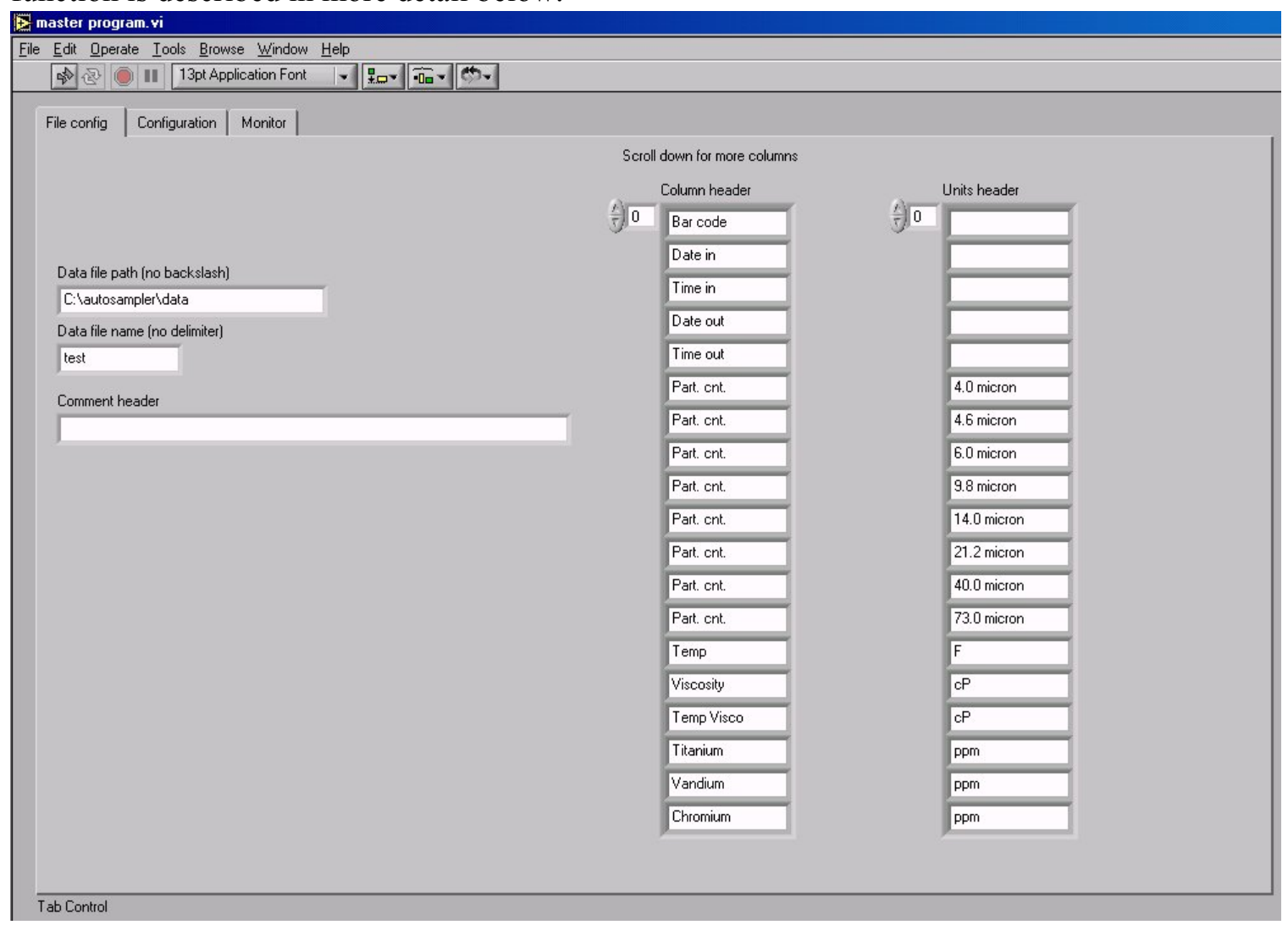

Figure 1. File configuration screen.

Data file path (no backslash). This sets the path where the data file will be written. The default is $\mathrm{C}$ : lautosamplerldata. If this default directory is changed it is important to insure that the directory exists or the program will give an error message. 
Data file name (no delimiter). This sets the initial part of the data file name. The naming convention for data files is Data file name-Dmonth_day_year-Thour_minutes_sec.csv. An example of a data file name using the default value in the Data file name (no delimiter) field might be test-D04_14_2004T03_45_28.csv. Where the date $04 / 14 / 2004$ is the date when the file was created and $03: 45: 28$ is the hour, minute and second when the file was created. This convention is used to prevent the accidental overwriting of data files. A new file is created every time the program is restarted.

Comment header. This field allows comments to be placed into the first row of the data file.

Column header and Units header. This sets the headers for the data file. Under normal circumstances, these values will not be changed.

Note. The NDIR channels are contained in a separate file in the C:lautosamplerlconfiguration directory. The file is default.ndi and is preset to the customer selected NDIR channels. The wave numbers for these channels are preset in the units header column.

\section{Configuration Screen}

Figure 2 shows the configuration screen. This is the screen that you will see when the program first starts so that the operator can set the operating conditions before initiating a sample run. The screen is used to set the operating conditions for the instruments and the auto sampling unit. The default values on this screen are set to allow the unit to test the most viscous fluids that will be encountered in the customer's facility. These high viscosity fluids will take more time to draw from the sample bottle and be distributed to the instruments. If a batch of fluids with a lower viscosity is to be run, these values can be changed to decrease run time. The parameters are described below.

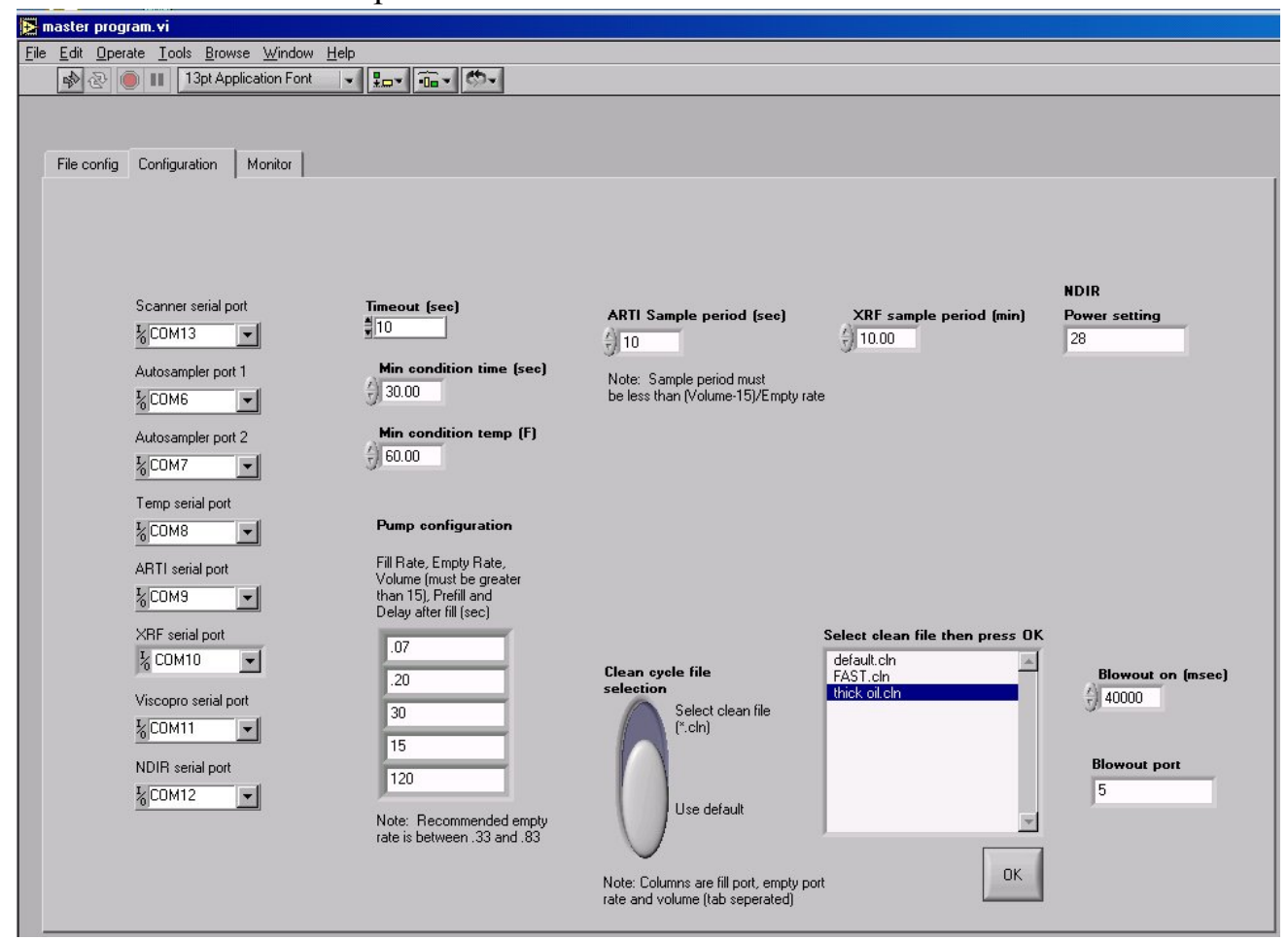

Figure 2. Configuration screen. 
Serial Port Settings. The left hand portion of this screen contains the serial port settings for each of the devices attached to the computer. These settings should not require changing. Settings for some of the instruments can be adjusted through these ports using HyperTerminal communication software and the serial commands in the attached manuals.

Timeout (sec). This sets the time that the program waits before reissuing commands in the event that there is a temporary break in communication. Generally this setting does not need to be changed.

Min conditioning time (sec) and Min conditioning temp (F). This sets the minimum time and temperature of the sample before it is allowed to leave the conditioning chamber. The best option in the event that the fluid is very cold is to adjust the conditioning time upward. The temperature in the conditioning chamber is maintained between 100-110 F.

Pump configuration. Using the proper pump configuration settings is extremely important to the proper operation of the instruments in the LIAB. There are 5 settings for configuring the pump. They are the fill rate of the pump $(\mathrm{ml} / \mathrm{sec})$, empty rate of the pump $(\mathrm{ml} / \mathrm{sec})$, sample volume $(\mathrm{ml})$, prefill $(\mathrm{ml})$, and delay after fill (sec). The fill rate and delay after fill insure that the sample to be tested is completely in the sample pump before dispensing the sample to the instruments. The default settings insure that the most viscous fluids can be properly sampled. If a series of fluids with lower viscosity are to be tested, the fill rate can be increased. The maximum allowable value for the fill rate is $15 \mathrm{ml} / \mathrm{sec}$. The empty rate is the rate at which the sample is dispensed to the instruments. The default setting allows the most viscous fluids to be dispensed to the instruments without stalling the pump. It is critical that the pump does not stall as this will affect the particle count and may result in fluid remaining in the chamber after the test. The optimal empty rate for the particle counter is between .33 and $.83 \mathrm{ml} / \mathrm{sec}$. The sample volume and prefill are set to insure that there is enough fluid for a complete test and that the particle counter is filled with fluid before starting a test. There should be no need to change these settings.

Arti Sampling Period (sec). This sets the sample period for the Arti Particle Counter. The sample period should be less than (fill volume-15)/empty rate. Normally there should be no need to change this setting.

XRF sample period (min). This sets the sample period for the XRF. Increasing the setting increases the accuracy of the metal contamination count. It may also need to be adjusted as the source in the XRF becomes depleted to obtain accurate measurements.

NDIR power setting. This sets the power for the NDIR. The setting should not be changed without consulting with the manufacturer of the NDIR as it is possible to damage the IR source if the setting is too high.

Clean cycle selection. This setting is used to select the cleaning cycle. If any cleaning cycle other than the default is going to be used, this must be set before running the program and the desired clean cycle selected from the list on the right. Clean cycles should have a cln extension to show up on the list. These files can be found in the directory $\mathrm{C}$ : $\backslash$ autosamplerlconfiguration. Each row in the clean cycle file sets the 
port that is used for filling the chamber, the port that the chamber is emptied into and the rate for the fill and empty. The default file has been designed to clean out every section of the instrument and may be used as an example creating a new file. Ports 3 and 4 are used for cleaning fluids. Port 5 is reserved for drawing air into the system to flush out any remaining fluid in the system. It is important that port 5 be kept clean as it can result in contamination of the samples if it is not. Figure 3 shows the fluid paths in the system and can be used to design a new clean cycle with the default clean cycle as a template. A normal clean cycle would draw air in through port 5 and send it through ports 0,1 and 2 to clean out residual fluid in the system. This would be followed by drawing cleaning fluid through either ports 3 or 4 and sent through ports 0,1 and 2 . Finally there should be at least one other air cycle to clean the cleaning fluid out of the system. The input file would look like the one shown below:

$\begin{array}{llll}5 & 0 & 15 & 100 \\ 5 & 1 & 15 & 100 \\ 5 & 2 & 15 & 100 \\ 3 & 0 & 15 & 100 \\ 3 & 1 & 15 & 100 \\ 3 & 2 & 15 & 100 \\ 5 & 0 & 15 & 100 \\ 5 & 1 & 15 & 100 \\ 5 & 2 & 15 & 100\end{array}$

The fill rate is $15 \mathrm{ml} / \mathrm{sec}$ and the volume is $100 \mathrm{ml}$ in each of the cycles.

Blowout on (msec) and Blowout port. These settings are used to complete the clean cycle by blowing pressurized gas through the instruments. The blowout on sets the time period for the blowout and the port setting makes sure that the air port 5 remains clean of residue. The on setting can be adjusted but the port setting should not be changed. 


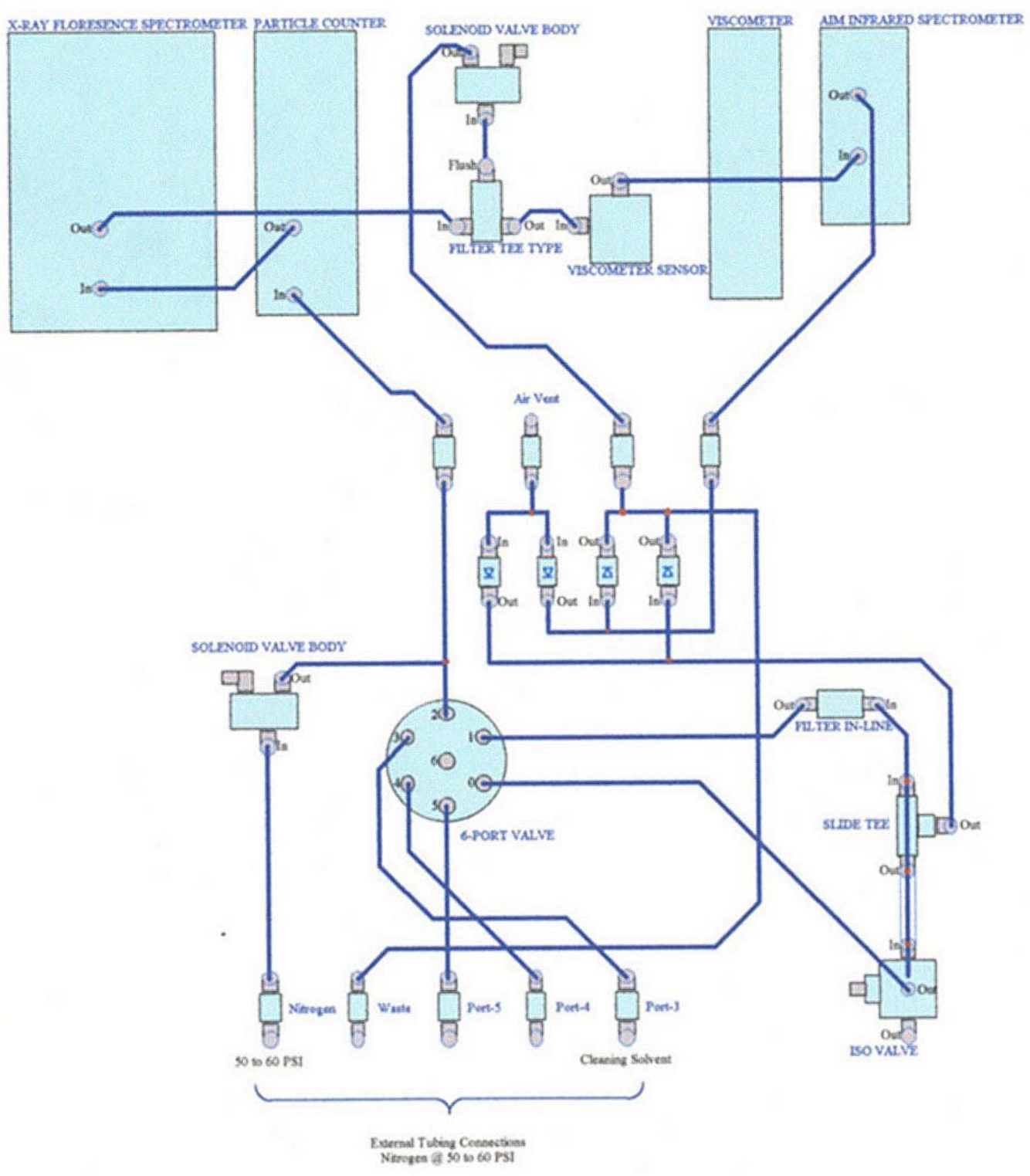

Figure 3. Tubing drawing of LIAB showing fill and empty ports. 


\section{Monitor Screen}

The monitor screen gives the status of the samples in the unit and the status of the instruments. In addition, it contains settings to unload the turret before starting a sample run and the option of turning off the clean cycle. Figure 4 shows the Monitor Screen.

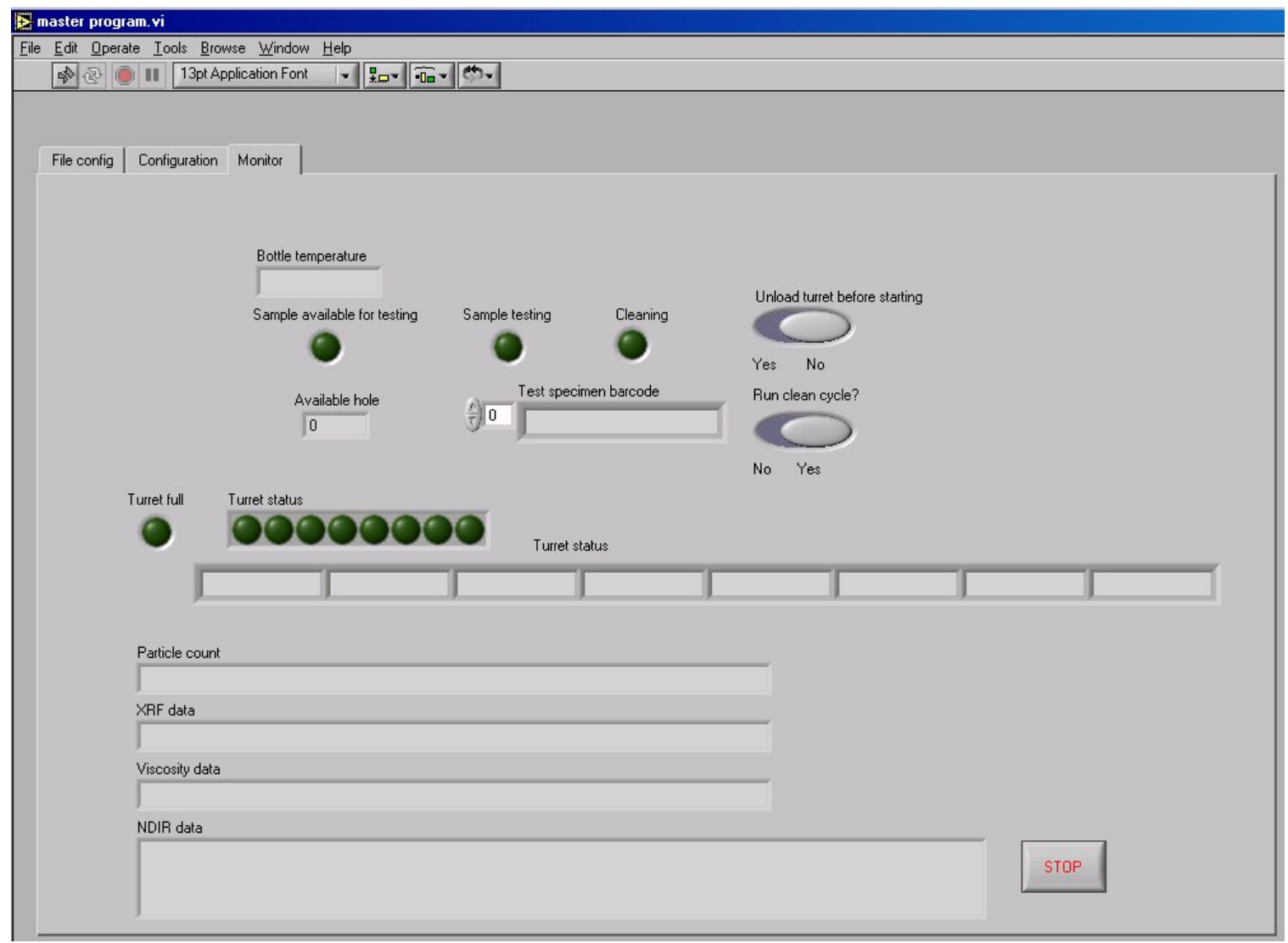

Figure 4. Monitor Screen.

Bottle temperature. This function is not implemented in this version of the software.

Sample available for testing, Sample testing and Cleaning. The first light indicates whether a sample has been conditioned long enough to be available for testing. The second light indicates whether a sample is being tested and the final light indicates if the sample is being cleaned. A sample cannot be testing while the clean indicator is on.

Available hole indicates the next available hole in the top turret that can accept a sample. Samples are tested on a first in first out basis.

Test specimen barcode tells the barcode of the sample that is being tested.

Turret full indicates that all 8 slots in the top turret have samples in them. 
Turret status indicates how many holes are full in the top turret of the sampler and gives the barcode of these samples.

Particle count, XRF data, Viscosity data and NDIR data show the last results of the last complete test. If the instrument does not produce data, the corresponding output will indicate that the instrument is off line.

Unload turret before start. If the unit crashes and the operator is uncertain whether there are still samples bottles in the unit, this can be set yes and the unit will unload all bottle holes in the top and bottom turrets before starting the normal sample cycle. This setting must be set before launching the program.

Run clean cycle? Normally this should be left to yes to insure that the machine is properly cleaned between samples. If multiple samples of the same specimen are to be run, this can be set to no to reduce the sample run time. This setting must be set before launching the program.

Stop. This button is used for the normal shutdown of the Master Program. It causes the orderly shutdown of the unit and is the preferred method of stopping the program. If this fails then the program can be aborted by pressing the stop sign in the upper left corner of the screen. This is not the recommended method of stopping the program as it does not result in an orderly shutdown of the unit. If the program is aborted, then it is necessary to cycle the power to the LIAB to insure that all of the subunits have been properly shutdown and restarted. Failure to do this can result in the LIAB in acting unpredictably since the microprocessors in the unit are not shut down when the abort is pressed. 


\title{
Appendix A \\ Instrument Specifications/Calibration Sheets
}

\author{
Arti Particle Counter \\ Specifications \\ Light Extinction Sensor
}

Sensitivity: $\quad 2 \mu \mathrm{m}$ (ISOMTD in oil)

Dynamic range: $\quad 2 \sim 100 \mu \mathrm{m}$ (ISOMTD in oil)

Flow Rate: $\quad 20-50 \mathrm{~mL} / \mathrm{min}$

Max. Operating Pressure: $\quad 6000$ psi

Calibration: Calibrated by PSL in water and ISOMTD in oil

Resolution: $\leq 10 \% @ 10 \mu \mathrm{m}$ with PSL calibration

Counting Efficiency: 30-70\%@2 $2 \mu \mathrm{m}, 90-110 \% @ 3 \mu \mathrm{m}$ (JIS)

Coincidence Loss: $10 \% @ 30,000$ particles/mL (PSL in water)

Wetted Materials: $\quad$ Sapphire and stainless steel

Light Source: $\quad$ Laser diode

Light Detector: $\quad$ PIN photo diode

Input Voltage: $\quad+5 \mathrm{VDC}$

Dimensions: $\quad 2$ " diameter X 7" long

Environment:

Operating: 40 to $105^{\circ} \mathrm{F}\left(4\right.$ to $41^{\circ} \mathrm{C}$ ) (environment specs)

55 to $105^{\circ} \mathrm{F}\left(12\right.$ to $\left.41^{\circ} \mathrm{C}\right)$ (fluid specs)

20 to $80 \%$ relative humidity, non-condensing

Storage: $\quad-40$ to $160{ }^{\circ} \mathrm{F}\left(-40\right.$ to $\left.70{ }^{\circ} \mathrm{C}\right)$

Up to $98 \%$ relative humidity, non-condensing 


\section{ARTI}

\section{Calibration Certificate}

This certifies the below mentioned Liquid Particle Counter System conforms to ISO11171:1999, Hydraulic Fluid Power Calibration of Automatic Particle Counters for Liquids. This system was calibrated with instruments and material traceable to international standards by factory authorized and trained technicians.

Note: The symbol $\mu \mathrm{m}(\mathrm{c})$ indicates ISOMTD particle size calibration according to ISO 11171:1999.

$\begin{array}{rc}\text { Date of Calibration : } & \text { October } 29,2003 \\ \text { Calibration Due Date: } & \text { October } 29,2004 \\ \text { Temperature: } & 22^{\circ} \mathrm{C}\left( \pm 1^{\circ} \mathrm{C}\right) \\ & \end{array}$

Instrument Model:

Serial Number: 30909407

Relative Humidity: $31 \%( \pm 7 R . H$.

Equipment used for calibration:

\begin{tabular}{|c|c|c|c|}
\hline Type & Model & Serial Number & Calibration Due Date \\
\hline PHA & RION KH-02A & 20280160 & 7 July 2004 \\
\hline $100 \mathrm{ml}$ Graduate & PYREX 3002-100 & $\mathrm{C} 28763$ & \\
\hline Stopwatch & VWR & MET0473 & 5 Feb. 2004 \\
\hline Reference PC & ARTI PODS & P1000-099 & 12 Feb. 2004 \\
\hline Reference Particles & NIST SRM-2806 & Lot \# 5-60-B & 31 Dec. 2003 \\
\hline
\end{tabular}

Instrument Calibration Data:

\begin{tabular}{|c|c|c|c|}
\hline Particle Size $(\mu \mathrm{m}(\mathbf{c}))$ & Threshold Setting (mV) & Particles Ref. Lot \# & Calibration Reference Material \\
\hline 4.0 & 55.5 & B101A & NIST 8631 Medium Test Dust \\
\hline 4.6 & 93.0 & B101A & NIST 8631 Medium Test Dust \\
\hline 6.0 & 255.0 & B101A & NIST 8631 Medium Test Dust \\
\hline 9.8 & 790.0 & B101A & NIST 8631 Medium Test Dust \\
\hline 14.0 & 1315.0 & B101A & NIST 8631 Medium Test Dust \\
\hline 21.2 & 2150.0 & B101A & NIST 8631 Medium Test Dust \\
\hline 40.0 & 2902.0 & 19989 & NIST Traceable Soda Lime Glass (DUKE) \\
\hline 73.0 & 3771.0 & 20283 & NIST Traceable Soda Lime Glass (DUKE) \\
\hline
\end{tabular}

Verification of Particle Counting Accuracy: (NIST RM 8632 ISOUFTD Lot \# A75)

\begin{tabular}{|c|c|c|}
\hline 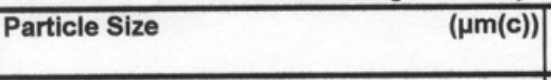 & $\begin{array}{c}\text { Expected Particle } \\
\text { Concentration }(\mathrm{p} / \mathrm{ml})\end{array}$ & $\begin{array}{c}\text { Observed Particle } \\
\text { Concentration }(\mathrm{p} / \mathrm{ml})\end{array}$ \\
\hline 3.0 & $8600-13000$ & 10669.0 \\
\hline 4.0 & $5400-8100$ & 7808.0 \\
\hline 5.0 & $3300-4500$ & 4484.0 \\
\hline 6.0 & $1500-2500$ & 2429.0 \\
\hline 10.0 & $58-220$ & 170.0 \\
\hline 14.0 & $4.1-19$ & 15.0 \\
\hline
\end{tabular}

Technician

D. W. Stantas 


\section{Non-dispersive Infrared Analysis}

The Non-dispersive infrared analysis (NDIR) is manufactured by Belhaven Applied Technologies. NDIR can measure infrared absorption for up to 32 channels in the 2.5 to 12 micron range (other ranges can be requested). Typical precision per band is given in Table 1 below.

\begin{tabular}{|l|l|l|l|l|}
\hline Wavelength (microns) & 0.8 & 2.9 & 5.7 & $6-9$ \\
\hline $\begin{array}{l}\text { Precision (average percent } \\
\text { error) }\end{array}$ & 0.4 & 0.013 & 0.23 & 0.62 \\
\hline
\end{tabular}

Table 1. Typical precision per band for non-dispersive infrared analyzer.

A comparison of NDIR results with standard laboratory measurements for water and TAN are given in Table 2 below. The NDIR is capable of measuring water content to $50 \mathrm{ppm}$ or less.

\begin{tabular}{|c|c|c|c|}
\hline System/Laboratory & \multirow[t]{2}{*}{ NDIR Spectroscopy } & \multirow[t]{2}{*}{ Oil Analysis Lab* } & \multirow[t]{2}{*}{ Navy Lab** } \\
\hline Parameter & & & \\
\hline Water Sample \#1 & $410 \mathrm{ppm}$ & $430 \mathrm{ppm}$ & $370 \mathrm{ppm}$ \\
\hline Water Sample \#2 & $440 \mathrm{ppm}$ & $450 \mathrm{ppm}$ & $380 \mathrm{ppm}$ \\
\hline TAN Sample \#1 & $0.70 \mathrm{mg} \mathrm{KOH} / \mathrm{g}$ & $0.70 \mathrm{mg} \mathrm{KOH} / \mathrm{g}$ & $0.64 \mathrm{mg} \mathrm{KOH} / \mathrm{g}$ \\
\hline TAN Sample \#2 & $0.77 \mathrm{mg} \mathrm{KOH} / \mathrm{g}$ & $0.70 \mathrm{mg} \mathrm{KOH} / \mathrm{g}$ & $0.64 \mathrm{mg} \mathrm{KOH} / \mathrm{g}$ \\
\hline \multicolumn{4}{|c|}{$\begin{array}{l}\text { * Data provided by Oil Analysis Lab, Spokane, Wa } \\
\text { * Water by Karl Fischer, ASTM D1744, TAN by ASTM D664 }\end{array}$} \\
\hline
\end{tabular}

Table 2. Comparison of NDIR results with laboratory measurements.

This unit is shipped with the following 5 filters as specified by Pall Corporation:

\begin{tabular}{|l|l|l|l|l|}
\hline Item Number & Wavelength & Wavenumber & Additive & $\begin{array}{l}\text { Additive } \\
\text { Wavenumber }\end{array}$ \\
\hline NB-2730-022 & $2730 \mathrm{~nm}$ & $3663 \mathrm{~cm}-1$ & phenolic antioxidant & $3648 \mathrm{~cm}-1$ \\
\hline NB-5730-080 & $5730 \mathrm{~nm}$ & $1745 \mathrm{~cm}-1$ & oxidation by-products & $1750 \mathrm{~cm}-1$ \\
\hline BP-8590-115 & $8590 \mathrm{~nm}$ & $1164 \mathrm{~cm}-1$ & sulfonate detergent & $1169 \mathrm{~cm}-1$ \\
\hline BP-9750-280 & $9750 \mathrm{~nm}$ & $1025 \mathrm{~cm}-1$ & $\begin{array}{l}\text { ZDDP (P-O-C) } \\
\text { additive }\end{array}$ & $978 \mathrm{~cm}-1$ \\
\hline
\end{tabular}




\section{ViscoPro 1500}

\section{General Specifications}

\section{Sensors}

Piston Range

Dynamic Range

Maximum Temperature

Maximum Recommended Pressure

Wetted Metals

\section{Electronics}

Temperature Units

Operating Temperature

Relative Humidity

Primary Power

\section{System}

Viscosity Accuracy

Viscosity Repeatability

Temperature Accuracy

Temperature Repeatability

Measurement Period
See Certificate of Calibration

20 to 1

$190^{\circ} \mathrm{C}\left(374^{\circ} \mathrm{F}\right)$

$1000 \mathrm{psi}$

316L and 430 Stainless Steel

Fahrenheit or Celsius

$10^{\circ} \mathrm{C}-65^{\circ} \mathrm{C}\left(50^{\circ} \mathrm{F}-150^{\circ} \mathrm{F}\right)$

$10-95 \%$, non-condensing.

18-36 VDC 


\subsection{Certificate of Calibration}

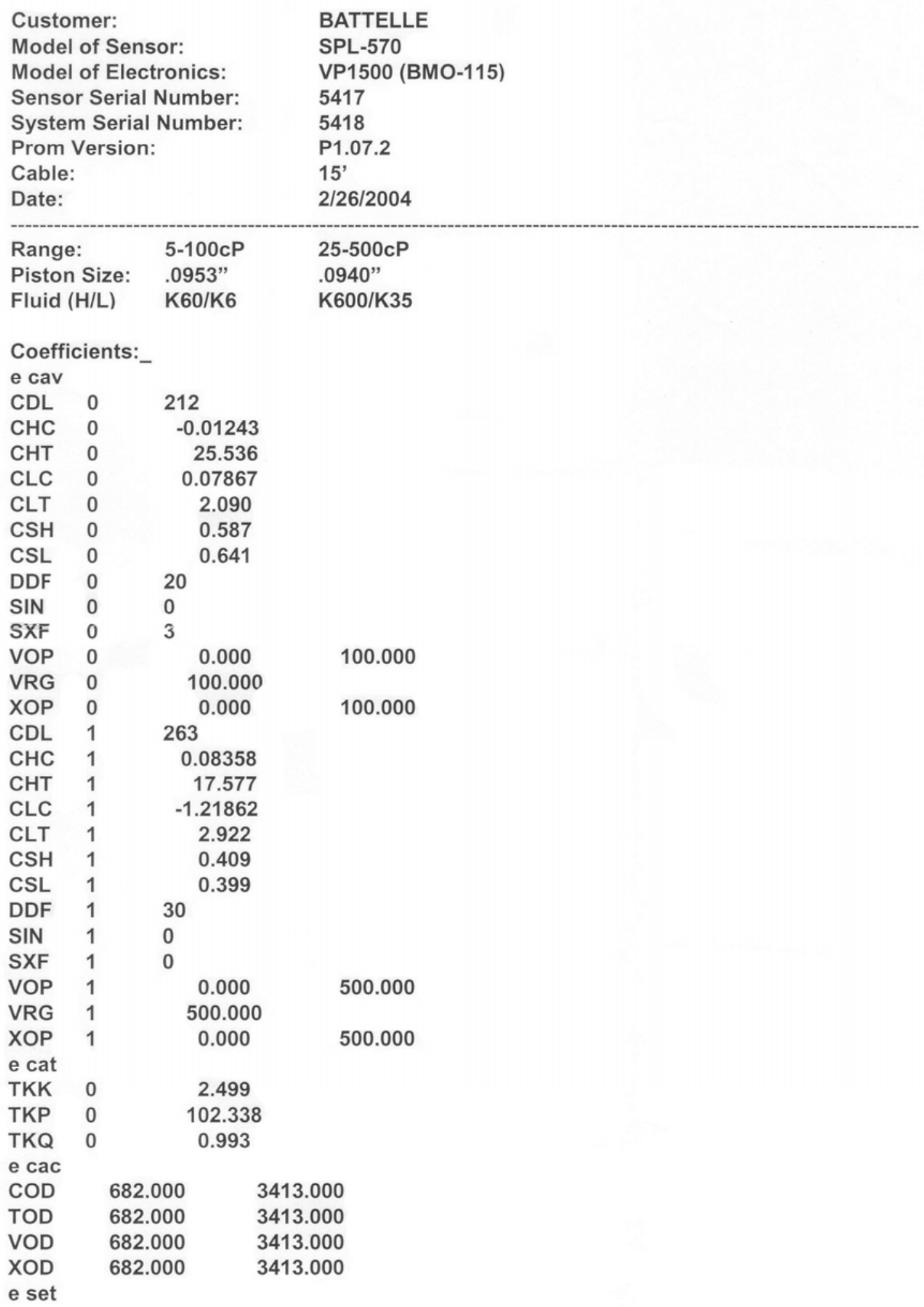




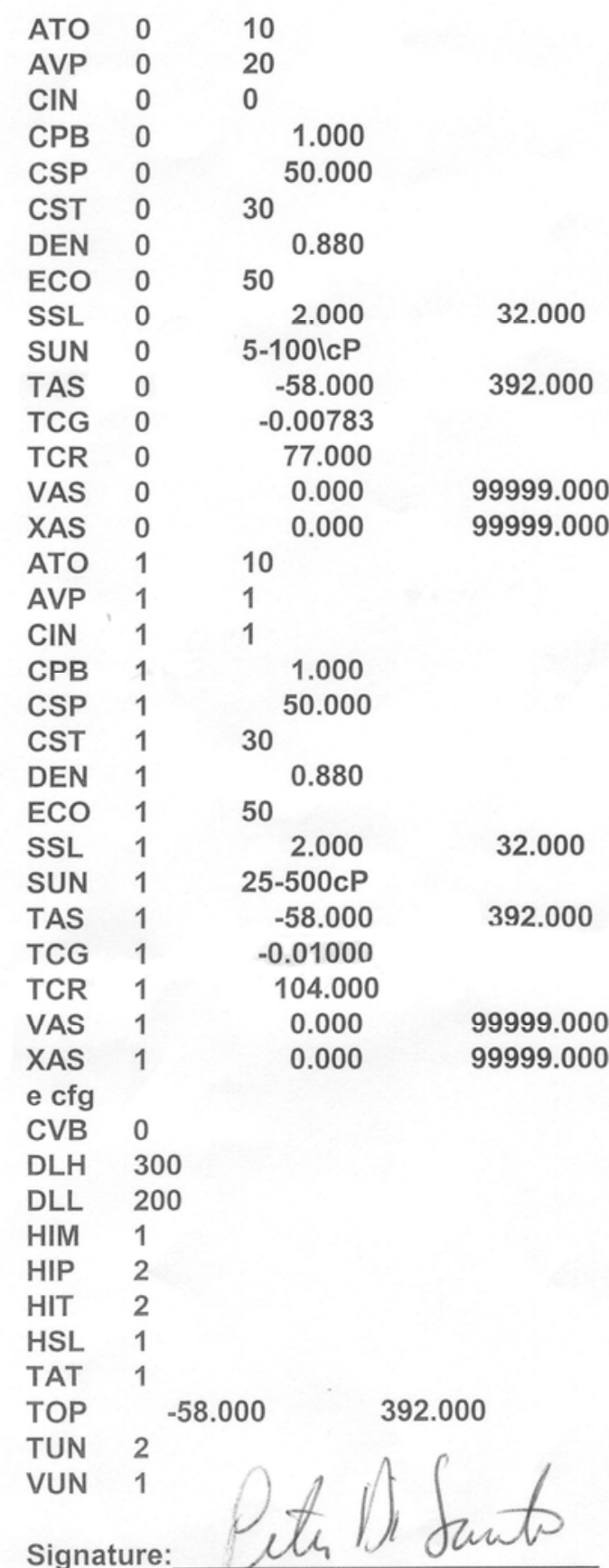

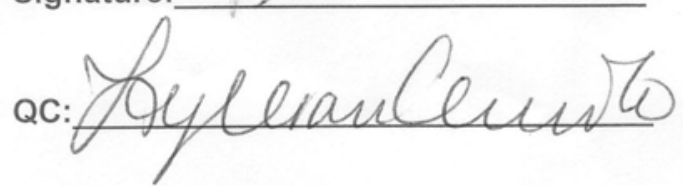

Date: $2-26-0 y$

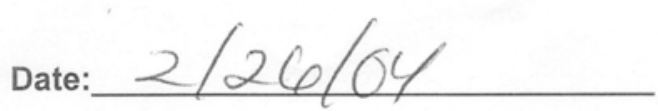




\section{X-ray fluorescence spectroscopy}

The standard source configuration for the XRF is ${ }^{109}$ Cadnium. There is no limit on the particle size for $\mathrm{x}$ ray fluorescence spectroscopy measurements. Table 3 below lists the elemental detection limits at 10 percent precision for the standard configuration for the LIAB.

\begin{tabular}{|l|l|l|l|l|l|}
\hline Element & $\begin{array}{l}\text { Detection } \\
\text { Limit }(\mathbf{p p m})\end{array}$ & $\begin{array}{l}\text { AOAP } \\
\text { Calibration } \\
\mathbf{( p p m )}\end{array}$ & Element & $\begin{array}{l}\text { Detection } \\
\text { Limit (ppm) }\end{array}$ & $\begin{array}{l}\text { AOAP } \\
\text { Calibration } \\
\mathbf{( p p m )}\end{array}$ \\
\hline Aluminum & $\mathrm{ns} *$ & 10 & Nickel & $5-10$ & 10 \\
\hline Boron & $\mathrm{ns}$ & 100 & Silicon & $\mathrm{ns}$ & 10 \\
\hline Chromium & $1-3$ & 10 & Silver** & $1-3$ & 10 \\
\hline Copper & $5-10$ & 10 & Sodium & $\mathrm{ns}$ & 10 \\
\hline Iron & $1-3$ & 10 & Tin & 10 & 10 \\
\hline Lead & $1-3$ & 10 & Titanium & $3-5$ & 10 \\
\hline Magnesium & $\mathrm{ns}$ & Zinc & $1-3$ & 100 \\
\hline Molybdenum & $3-5$ & 10 & & \\
\hline *ns = Not in standard configuration of XRF. \\
\hline ** Requires ${ }^{241}$ Americium source. \\
\hline
\end{tabular}




\section{Distribution}

No. of

Copies

Onsite

4 Pacific Northwest National Laboratory

$\begin{array}{ll}\text { L. O. Casazza (1) } & \text { P7-07 } \\ \text { A. F. Pardini (1) } & \text { K5-26 } \\ \text { M. L. Watkins (1) } & \text { K5-26 } \\ \text { W. C. Weimer (1) } & \text { K9-09 }\end{array}$

Distr-1 